Article

\title{
Exploring R\&D Influences on Financial Performance for Business Sustainability Considering Dual Profitability Objectives
}

\author{
Kao-Yi Shen ${ }^{1, *} \mathbb{1}$, Min-Ren Yan ${ }^{2}$ and Gwo-Hshiung Tzeng ${ }^{3}$ \\ 1 Department of Banking \& Finance, Chinese Culture University (SCE), Taipei 11114, Taiwan \\ 2 Institute of International Business Admin., Chinese Culture University (SCE), Taipei 11114, Taiwan; \\ mjyen@sce.pccu.edu.tw \\ 3 Graduate Institute of Urban Planning, National Taipei University, New Taipei City 23741, Taiwan; \\ ghtzeng@mail.ntpu.edu.tw \\ * Correspondence: atrategy@gmail.com; Tel.: +886-2-2700-5858-8676 (ext. 8676)
}

Received: 29 September 2017; Accepted: 26 October 2017; Published: 27 October 2017

\begin{abstract}
The importance of research and development (R\&D) for business sustainability have gained increasing interests, especially in the high-tech sector. However, the efforts of R\&D might cause complex and mixed impacts on the financial results considering the associated expenses. Thus, this study aims to examine how R\&D efforts may influence business to improve its financial performance considering the dual objectives: the gross and the net profitability. This research integrates a rough-set-based soft computing technique and multiple criteria decision-making (MCDM) methods to explore this complex and yet valuable issue. A group of public listed companies from Taiwan, all in the semiconductor sector, is analyzed as a case study. More than 30 variables are considered, and the adopted soft computing technique retrieves 14 core attributes-for the dual profitability objectives-to form the evaluation model. The importance of R\&D for pursuing superior financial prospects is confirmed, and the empirical case demonstrates how to guide an individual company to plan for improvements to achieve its long-term sustainability by this hybrid approach.
\end{abstract}

Keywords: business sustainability; research and development (R\&D); multiple criteria decision-making (MCDM); financial objective; variable-consistency dominance-based rough set approach (VC-DRSA); internetwork relationship map (INRM); directional flow graph (DFG)

\section{Introduction}

The importance of research and development $(R \& D)$ for the high-tech industry has been discussed broadly; moreover, the relationship between $R \& D$ efforts and financial prospects has gained surging interests in the recent years. Owing to the intensive competition and rapid advances in the global business environment, high-tech companies have to invest in R\&D to maintain or strengthen their market competitiveness. Previous studies [1,2] have argued that R\&D could be regarded as a driving force for productivity, and the others have claimed that R\&D efforts and product innovations would help firms to capture market share and contribute to the profitability [3-5] in U.S. and Canada. Although most of the researchers would agree that R\&D activities are the driving force to achieve innovations, the influences of $R \& D$ to the financial performance (FP) of high-tech companies are still unclear, which need further investigations.

Similar to R\&D efforts, it has been argued by certain research [6] that patents may act as an intermediate role to protect innovations, creativities and R\&D outcomes, and contribute to the profitability of companies. On one side, MacDonald [7] examined the effect of patents on FP and found mixed results; on the other side, Artz et al. [8] found a negative relationship between patents and 
FP from the observed 272 firms that were listed in the U.S. stock market. It still lacks consensus or universal pattern on the influence of $R \& D$ or patents on FP, because the spending on $R \& D$ or patents is not only a plus to value creation but also a deduction item on the income statement. Few studies have attempted to analyze the impact of R\&D efforts for improving FP on the gross (before deducting R\&D spending) and the net profitability simultaneously. Therefore, the central purpose of this study is to deepen our understanding of the influence of $R \& D$ on FP for the two financial prospects: the gross and the net profitability, which are critical to business sustainability in the long-term. Furthermore, this study manages to support an individual company to improve its FP considering the complex and imprecise relationships among $R \& D$ and critical financial factors in a real business environment.

High-tech industry has been growing increasingly above the average of sectors that delivers significant impact on worldwide technological innovations and economic developments [9]. Among various high-tech sectors, the semiconductor industry is crucial in facilitating new technologies and product development. Take 3C (i.e., Computers/Communications/Consumer) products as an example, which depend on integrated circuit (IC) design to enable new functionalities, and the sizes/costs of new ICs decrease in each generation by the advances in semiconductor manufacturing techniques. Based on the statistics from Semiconductor Industry Association (SIA), the worldwide market of the semiconductor has been estimated at more than 334 billion USD in 2016, and the global sales are increasing in 2017. Top-ranked semiconductor sales leading companies such as Intel headquartered in U.S., TSMC headquartered in Taiwan, Samsung headquartered in South Korea, and Japan's Toshiba are world-class technological giants that drive the development of innovative products and the economy. The four world leading semiconductor companies all invested significantly on R\&D. Nevertheless, the financial outcomes of TSMC and Toshiba were diverse in the past three years. In mid/2017, TSMC reached its peak market value by showing outstanding earnings per share (its 2016 EPS reached 12.89 TWD, the highest figure in the recent three years) with a high growth momentum; on the contrary, the semiconductor business of Toshiba was sold out owing to its consecutive financial losses. The crucial link between R\&D and FP deserves high attention.

According to a report from the U.S. Department of Commerce, the sales of Taiwan semiconductor industry was about USD 71 Billion in 2015 [10], which is among the top three leading countries in the world. The semiconductor industry has led the economic growth and migration in Taiwan since the last decade, and the understanding of how R\&D efforts may influence the FP in this industry is highly valuable in practice [11]. As a result, a real case of the semiconductor companies from Taiwan is adopted to explore the intricate patterns between R\&D and FP prospects.

Given the above research purposes, three major research questions to be addressed are as follows: (1) What are the contextual relationships of $R \& D$ and individual financial indicators on the FP of the semiconductor industry? (2) What are the relative importance of the critical R\&D and financial variables that may influence the profitability of semiconductor companies? (3) How could a semiconductor company identify the priority to improve its FP based on the self-defined emphasis on the gross and the net profitability objectives? In a complex business environment, it often requires to consider a significant amount of variables (attributes) with interrelated or partially related relations; conventional statistical methods (e.g., multiple regression) would encounter obstacles to tackle this kind of complicated problems. Therefore, to answer the research questions as mentioned above, a hybrid multiple criteria decision-making (MCDM) model/approach is proposed in this study. Compared with the previous research that mainly relied on statistics to examine the relationship between R\&D and subsequent performance, the present study not only tries to distinguish the influence of R\&D on the gross and the net profitability but also can support and guide a company to reach its financial target. It is, therefore, the aim of the proposed approach to find the imprecise knowledge from historical data and support semiconductor businesses to plan for R\&D or financial strategy based on their expected profitability objectives. The overall research concept is illustrated in Figure 1.

The remainder of this paper is structured as follows. In Section 2, it briefly reviews the influence of R\&D on FP and the adopted research methods. Section 3 introduces the proposed hybrid model. 
Section 4 examines the proposed approach by analyzing a group of semiconductor companies in Taiwan as a case study and uses a semiconductor company's actual data to illustrate the idea of improvement planning. In the final section, the concluding remarks are provided, and some limitations of the proposed approach are discussed.

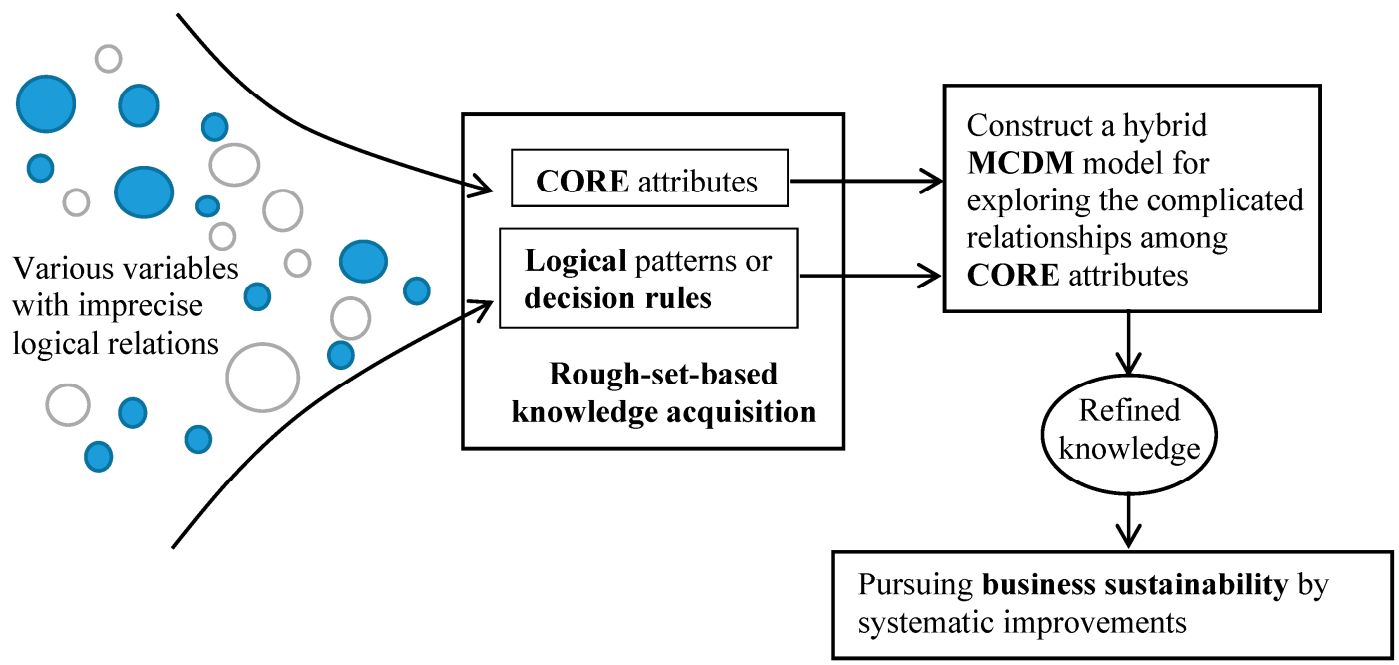

Figure 1. Conceptual framework of this research.

\section{Literature Review and Background of Research Methods}

In this section, how the R\&D efforts might influence high-tech companies is discussed. Besides, the proposed hybrid approach comprises of several MCDM and soft computing techniques; therefore, the background and the financial applications by the adopted methods and are briefly reviewed.

\subsection{RED Influence on High-Tech Companies}

Previous studies argued that R\&D is a key factor for high-tech companies to compete and thrive under intensive global competitions [11,12]. Empirical studies on R\&D intensive companies and high-tech industry clusters have found higher production economics and added values [13]. Nevertheless, empirical evidence was mixed to the relation between R\&D efforts and the subsequent FP of firms. For example, R\&D intensity and R\&D workforce were found to be positive predictors for FP in the semiconductor industry [14]; also, the information technology (i.e., R\&D) investments revealed positive influences to the FP of companies in China. However, Artz et al. [1] found a negative relationship between $R \& D$ and firm performance. It seems that the influence of $R \& D$ or patents varies in different circumstances, as the constraints and strategies of companies are not always the same.

Recently, the relationship among financial constraints, R\&D efforts, and cash holdings has been noticed [15]. As the marginal value of R\&D spending is higher for the financially constrained companies, those constrained companies might be more sensitive to the financial returns brought by R\&D investments. Li [16] explored the mixed relationship among financial constraints, R\&D investment, and the stock performance (a leading indicator of FP); the positive relation between R\&D investment and return were only significant for those constrained companies.

Some other researchers [17] claimed that companies mainly rely on internal funding to support $R \& D$ activities; the relationship between financing constraints and $R \& D$ investments is significant. In this research thread, the present study also hopes to explore the contexts (e.g., the status of capital structure and cash flow) that need to be considered for semiconductor companies while forming their R\&D strategies. According to the previous study [18], research on the influence of R\&D efforts or patents for the FP of companies, consider multiple financial constraints or criteria are still rare and underexplored. Therefore, this study attempts to propose a hybrid approach-based on the 
machine learning capability of the soft computing and the decision model formed by domain experts' experience-to explore this important issue.

\subsection{Rough Set and Rule-Based Hybrid Decision Model for Financial Applications}

Rough set related research have become an emerging field in soft computing $[19,20]$, which has strength in modeling the vagueness and impreciseness of data. Although the classical rough set theory (RST) has gained positive outcomes in handling various classification problems, it ignores the so-called "dominance" relationship, which is critical to resolving decision-making problems. Therefore, the famous RST research group IDSS (Laboratory of Intelligent Decision Support Systems) proposed the dominance-based rough set approach (DRSA) [21] and variable consistency DRSA (VC-DRSA) [22] by analyzing the dominance relationship among attributes. One of the advantages of DRSA/VC-DRSA is that it may generate a set of "IF antecedents, THEN consequence" rules, which is easy to be comprehended by DMs, and it has been applied to solve several financial problems in the recent years. Examples are predicting financial distress [23], diagnosing the financial performance of banks [24] and life insurance companies [25], technical analysis for investment [26], and portfolio selection [27].

Considering the complexity of R\&D efforts on the FP of high-tech companies, it is our hope to explore its influences in a contextual approach; the decision rules obtained by DRSA/VC-DRSA may pave a road to meet this end. Furthermore, decision rules could be integrated with the findings from DEMATEL technique (refer Sections 2.3 and 3.2), which may suggest the directional influences of R\&D in each context in the form of directional flow graph (DFG) [28]. The implications from DFG may thus unravel the likely impact of $R \& D$ efforts on the financial prospects for the semiconductor industry.

\subsection{Multiple Criteria Decision-Making (MCDM) Methods in Finance}

Real business problems, such as FP prediction or evaluation for stocks, are often complex, imprecise, and ill-defined [29,30]. It is well recognized that there are often more than one variable/criterion regarding the evaluation or prediction of the target variable; furthermore, the considered criteria are often interrelated, which causes the complexity of modeling in practice.

The mainstream social science research adopts statistical methods to describe or examine the relations among the independent and explained variables, which is based on some unpractical assumptions-such as the independence of the considered variables and the probabilistic distributions of variables-in statistics [31]. Moreover, statistical outcomes from regressions only represent the average results [32], which are not capable of identifying contextual relationships considering the specific situations/constraints of an individual company. As a result, there is a rising trend in adopting MCDM methods, which has strength in considering all relevant and interrelated criteria, to resolve real-world problems [30,31].

Although there are several sub-fields in MCDM research, for brevity, only the methods/techniques considered in the proposed approach are discussed in here. First, to explore the plausible influential relationships among all the considered criteria, the DEMATEL technique $[33,34]$ is incorporated into the analytic network process (ANP) [35] method in MCDM. The DEMATEL method was proposed to evaluate complicated social problems assuming that all criteria have influences on each other, which has been successfully applied in identifying cause-effect influences for various applications, such as evaluating the improvement strategies of public open space for elderly people [36] and new technology [37]. The integration of DEMATEL and ANP may help adjust the dimensional weights in the classical ANP method, which also simplifies the design of questionnaire for collecting DMs' opinions [38]. Therefore, the DEMATEL-based ANP (DANP) method is adopted in the proposed model to evaluate the importance of R\&D and certain financial attributes for modeling.

Second, as the primary goal aims to support improvements in business sustainability, the modified VIKOR is adopted for evaluating and aggregating performance gaps on the considered criteria. Inspired by the idea of the previous works [39]. The classical VIKOR [40] uses an aggregation function to synthesize the performance gaps on all criteria, and form the final ranking outcome. However, it 
only uses the best/worst value of the evaluated alternatives on each criterion for calculations, which might compel DMs to select a relatively good choice among a group of inferior options.

To overcome this limitation, the modified VIKOR was proposed [30,31] by using the ideal/aspired value on each criterion to form an aggregation function, which could identify the priority gaps for a systematic improvement planning. The new approach, based on the modified VIKOR, contributed to a continuous improvement in, which is the essence of sustainability.

\section{Hybrid Model for Exploring R\&D Influences and Performance Gaps}

This Section explains the proposed hybrid approach. At the beginning, the financial and R\&D data need to be discretized to form two sets: the training and testing sets. The training set is adopted to conduct VC-DRSA approximations (explained in Section 3.1), to explore the CORE attributes and the associated rules with the net and the gross profitability; the testing set is used to examine its validity. Those two groups of CORE attributes are analyzed by the DEMATEL technique to identify the cause-effect relationships among them for supporting improvement planning.

The analysis of the DEMATEL cause-effect analysis can be combined with strong decision rules to form the influential network relation map (INRM) and directional flow graph (DFG). In the final stage, the modified VIKOR method can aggregate each alternative's input data to generate a ranking decision. The INRM, DFG, and modified VIKOR, all support for a systematic improvement planning that may lead to the long-term sustainability of a business. The following Sections 3.1-3.4 explain the mathematical operations and logics of the involved methods.

\subsection{Rough Set Theory and Its Extensions for Decision Aids}

Extended from the classical RSA, VC-DRSA may further consider the dominance relationships in attributes, which can be described by a 4-tuple information system $(I S=(U, A, V, f))$ with a controlled level of consistency among the data set. In an IS, the set $U$ is a finite set of universe, and the set $\mathrm{A}$ is a finite set of attributes (i.e., two subsets $C$ and $D$, where $C$ denotes the condition set, $D$ the decision one; $C \cap D=\varnothing) . V_{a}$ is the value domain of an attribute $a$, where $f: U \times A \rightarrow V$ denotes a mapping function, in which $f(x, a) \in V_{a}$ for each $a \in A$ and $x \in U$. In the proposed hybrid MCDM model, various financial ratios and $R \& D$ indicators of a company at the time $t-1$ are regarded as the condition attributes, and the FP (in the measure of gross or net profitability) at the time $t$ the decision attribute.

In the next, $\succeq_{a}$ denotes a complete outranking relation on set $U$ regarding the attribute $a$ (for each $a \in A$. For any two $x, y \in U$, " $x \succeq_{a} y$ " denotes that $\mathrm{x}$ is at least not worse than $\mathrm{y}$ on the attribute $a$. If $\succeq_{a}$ represents a complete outranking relationship, then $\mathrm{x}$ and $\mathrm{y}$ are always comparable with respect to the attribute $a$. Besides, $C l=\left\{C l_{k}, k=1, \ldots, h\right\}$, which is defined as a set of $\mathrm{h}$ decision classes (DCs) in $U$. Then, in a preferred order of DCs, if $q \succ k$, which indicates that $C l_{q} \succ C l_{k}$. Thus, the upward union and downward union of DCs can be defined as: (1) $C l_{k}^{\geq}=\cup_{s \geq k} C l_{s}$ and (2) $C l_{k}^{\leq}=\underset{s \leq k}{\cup} C l_{s}$. In the following explanations, only the upward union is illustrated for brevity.

The dominance relation $\operatorname{Dom}_{P}$ for $P \subseteq C$ can be defined by the aforementioned upward union. If an object (or alternative) $x P$-dominates y regarding $P$, then $x \succeq_{a_{i}} y$ for all $a_{i} \in P \subseteq C$, denoted as $x \operatorname{Dom}_{P} y$. For any $x, y \in U$, the dominating and dominated sets regarding $\mathrm{P}$ can be described as $\operatorname{Dom}_{P}^{\uparrow}(x)=\left\{y \in U: y \operatorname{Dom}_{P} x\right\}$ and $\operatorname{Dom}_{P}^{\downarrow}(x)=\left\{y \in U: x \operatorname{Dom}_{P} y\right\}$ respectively. The $P$-lower and $P$-upper approximations of the upward union $C l_{k}^{\geq}$can be denoted as $\underline{A P}\left(C l_{k}^{\geq}\right)$and $\overline{A P}\left(C l_{k}^{\geq}\right)$, where $\underline{A P}\left(C l_{k}^{\geq}\right)=\left\{x \in U: \operatorname{Dom}_{P}^{\uparrow}(x) \subseteq C l_{k}^{\geq}\right\}$and $\overline{A P}\left(C l_{k}^{\geq}\right)=\left\{x \in U: \operatorname{Dom}_{P}^{\downarrow}(x) \cap C l_{k}^{\geq} \neq \varnothing\right\}$ for $k=2, \ldots, h$. The $P$-lower and $P$-upper approximations thus construct the $P$-boundary region. The $P$-boundary of $\mathrm{Cl}_{k}^{\geq}$can be denoted as $\mathrm{Bou}_{P}\left(\mathrm{Cl}_{k}^{\geq}\right)$to represent the imprecise or boundary region. To define this boundary region, $\operatorname{Bou}_{P}\left(C l_{k}^{\geq}\right)=\overline{A P}\left(C l_{k}^{\geq}\right)-\underline{A P}\left(C l_{k}^{\geq}\right)$for $t=2, \ldots, h$. The $P$-lower approximation only includes the consistent objects in DRSA, which denotes the certain knowledge. 
However, VC-DRSA further allows for a controlled degree of inconsistency to include some additional objects in $\underline{A P}\left(\mathrm{Cl}_{k}^{\geq}\right)$.

For $C l_{k}^{\geq} \subseteq U$ and $v \in U$, the gain-type consistency measurement and a fixed gain threshold can be denoted as $\Theta_{X}$ and $\theta_{X}$, where $X$ denotes $C l_{k}^{\geq}$, and $\neg X \subseteq U$ while $\neg X=U-X$. The $\underline{A P}\left(C l_{k}^{\geq}\right)$with gain threshold $\theta_{X}$ can then be defined as $\underline{A P^{\theta_{X}}}\left(C l_{k}^{\geq}\right)=\left\{z \in C l_{k}^{\geq}: \Theta_{X}(v) \geq \theta_{X}\right\}$. The $P$-attributes-based upper and lower approximations of set $X$ could be used to define the $P$-boundary of set $X$ as $B o u_{P}^{\theta_{X}}=\overline{A P}^{\theta_{X}}(X)-\underline{A P}^{\theta_{X}}(X)$, and the detailed discussions of the gain-type consistency measure can be referred to the previous research [22].

In VC-DRSA, $\psi_{P}^{\theta_{X}}(X)$ denotes the percentage of all correctly classified objects for $P \subseteq C$ that satisfies consistency threshold $\theta_{X}$, and each minimal subset $P$ that can meet the requirement $\psi_{P}^{\theta_{X}}(X)=\psi_{C}^{\theta_{X}}(X)$ is termed as a REDUCT of $C$. The intersection of all REDUCTs is called a CORE $E_{X}$ of the IS in VC-DRSA, which represents the minimal and indispensable attributes to make VC-DRSA approximations without deteriorating its approximation quality. Those condition attributes in the CORE $\left(C O R E_{X}\right)$ set will be used for forming a hybrid MCDM model by DEMATEL, DANP, and the modified VIKOR (refer Figure 2). The object that complies with both the antecedents and consequence of a rule is termed as a support for the decision rule. The one with a high number of supports is called a strong rule.

Those DCs in set $X$, by the approximations of VC-DRSA, may generate a set of decision rules, in the form of "IF antecedent (premise), THEN consequence (decision)." The decision rules obtained from VC-DRSA would convey understandable knowledge considering the impreciseness and controlled level of inconsistency in data [22]. The VC-DRSA algorithm adopted in this work is based on the study [41], which is calculated by sequential covering rule and termed as VC-DomLEM. The required steps for VC-DRSA are as below, and the proposed approach needs to form two VC-DRSA models (take the gross and net profitability goals as the decision attribute separately in two sub-models). The two VC-DRSA models would induce two sets of CORE attributes to be integrated into a hybrid MCDM model.

Step 1 Discretize attributes. Discretized values may denote ideas like "high" and "low" to be close to how DMs process those concepts during reasoning. As a result, the obtained rules will be easier to be comprehended by DMs.

Step 2 Conduct VC-DRSA algorithm on data sets by various consistency thresholds until an acceptable outcome can be reached. Besides, the learned model will be validated by a testing set.

Step 3 Each trained VC-DRSA model would generate a CORE $\left(C O R E_{X}\right)$ set and a set of certain level of consistency in decision rules. The CORE comprises indispensable attributes for discerning the DCs. In the present study, two CORE sets associated with the gross and the net profit goals are the expected outputs, which will be used to form a hybrid MCDM model. This step is based on VC-DRSA approximation capability.

\subsection{Decision-Making Trial and Evaluation Laboratory (DEMATEL) Technique}

The DEMATEL technique is adopted for two purposes: find cause-effect influence relationships among the critical dimensions/attributes and use the basic concept of the ANP method to identify the influential weights by the DEMATEL-based-ANP (called DANP weights).

Step 4 Collect experts' opinions to form the direct influence relation matrix $\boldsymbol{B}=\left[b_{i j}\right]_{n \times n}$ that they feel the influence attribute $i$ has on another attribute $j$, expressed as $b_{i j}$, and form $\boldsymbol{B}$ in Equation (1). The scale of opinions ranges from 0 (zero influence) to 4 (extremely high influence), according to the knowledge or experience of experts. 


$$
\boldsymbol{B}=\left[\begin{array}{ccccc}
b_{11} & \cdots & b_{1 j} & \cdots & b_{1 n} \\
\vdots & & \vdots & & \vdots \\
b_{i 1} & \cdots & b_{i j} & \cdots & b_{i n} \\
\vdots & & \vdots & & \vdots \\
b_{n 1} & & b_{n j} & & b_{n n}
\end{array}\right]_{n \times n}
$$

As the proposed approach considers both financial objectives, the union set of the two VC-DRSA models' CORE attributes from Step 3 is used for the DEMATEL analysis, and the number of attributes in this union set equals $\mathrm{n}$ in Equation (1) for $1 \leq i \leq n$ and $1 \leq j \leq n$.

Step 5 Normalize $\boldsymbol{B}$ to obtain the direct influence relation matrix $\boldsymbol{D}$. The matrix $\boldsymbol{D}=\left[d_{i j}\right]_{n \times n}$ can be obtained by Equations (2) and (3), and a constant $\phi$ could be found to normalize $\boldsymbol{B}$.

$$
\begin{gathered}
\boldsymbol{D}=\phi \boldsymbol{B} \\
\phi=\min \left\{\frac{1}{\max _{i} \sum_{j=1}^{n} b_{i j}}, \frac{1}{\max _{j} \sum_{i=1}^{n} b_{i j}}\right\}, i, j \in\{1, \cdots, n\}
\end{gathered}
$$

Step 6 Using $D$ to get the total influence relation matrix $T$. As the indirect effects of the influence decrease as the power of $D$ increases, the total influence relation matrix $T$ can be redescribed as Equation (4). Therefore, the total influence relation matrix $T$ can be obtained from direct influence relation matrix $D$.

$$
\begin{gathered}
\boldsymbol{T}=\boldsymbol{D}+\boldsymbol{D}^{2}+\ldots+\boldsymbol{D}^{w}=\boldsymbol{D}\left(\boldsymbol{I}-\boldsymbol{D}^{w}\right)(\boldsymbol{I}-\boldsymbol{D})^{-1}, \text { and } \\
\boldsymbol{T}=\left[t_{i j}\right]_{n \times n}=\boldsymbol{D}(\boldsymbol{I}-\boldsymbol{D})^{-1} \text { while } \lim _{w \rightarrow \infty} \boldsymbol{D}^{w}=[0]_{n \times n}
\end{gathered}
$$

Step 7 Identify the cause-effect relationship of attributes by analyzing $T$. The sum of each row and sum of each column in $T$ may be indicated as $r_{i}^{A}\left(r_{i}^{A}=\sum_{j=1}^{n} t_{i j}\right.$, for $\left.j \in 1, \ldots, n\right)$ and $s_{j}^{A}$ $\left(s_{j}^{A}=\sum_{i=1}^{n} t_{i j}\right.$, for $\left.j \in 1, \ldots, n\right)$. Because the number of rows and columns both equal to $n$ ( $T$ is a square matrix), the operations of $r_{i}^{A}+s_{i}^{A}$ (for $\left.i=1, \ldots, n\right)$ would denote the central influence degree of the $i$ th criterion/attribute; in addition, the operations of $r_{i}^{A}-s_{i}^{A}$ (for $\left.i=1, \ldots, n\right)$ may divide criteria (attributes) into two group. If $r_{i}^{A}-s_{i}^{A}>0$, the $i$ th criterion belongs to the source group that has influence to the others; otherwise, the effect group. The cause-effect influence analysis by DEMATEL may be combined with VC-DRSA decision rules to indicate R\&D influential paths, termed as the direction flow graph (DFG). A case of how to develop a DFG will be demostrated in the next section.

\subsection{Hybrid DANP Model for Dual Financial Objectives}

The total influence relation matrix $\mathbf{T}$ from Step 6 is normalized to be $T_{A}^{\alpha}$ as Equation (5) for forming a hybrid DANP model, assuming that there are $\mathrm{m}$ dimensions and $n$ criteria in $\boldsymbol{T}_{A}^{\alpha}$. 


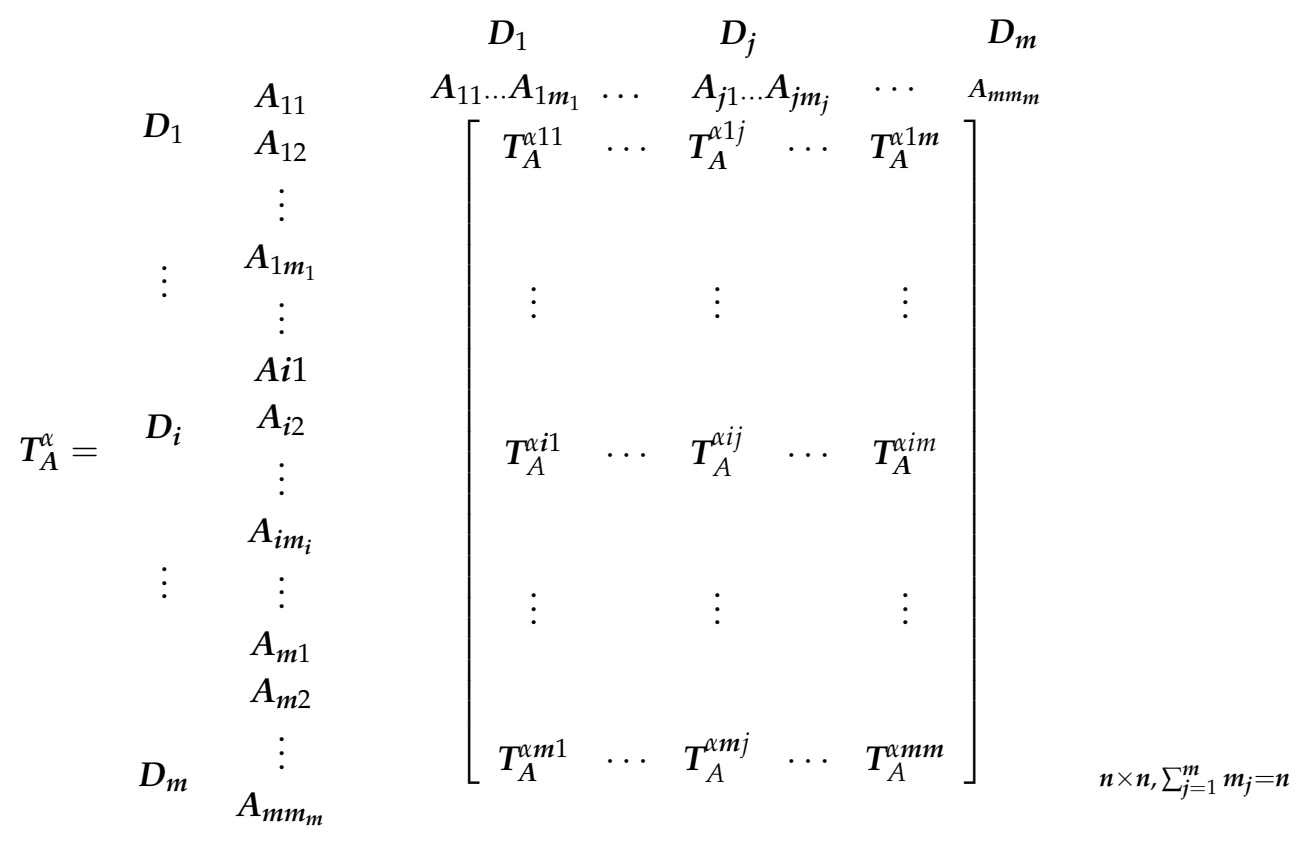

Step 8 Find the initial super-matrix for a DANP model. After the normalization of $T$, the initial super-matrix $W$ can be obtained by transposing $\boldsymbol{T}_{A}^{\alpha}$, denoted as $\boldsymbol{W}$ (i.e., $\boldsymbol{W}=\left(\boldsymbol{T}_{A}^{\alpha}\right)^{\prime}$ ). Furthermore, to adjust the equal-weight assumption among dimensions in the classical ANP method, the dimensional influence relation matrix $\boldsymbol{T}_{D}$ is normalized to become $\boldsymbol{T}_{D}^{\alpha}$ as in Equations (6) and (7).

$$
\begin{gathered}
\boldsymbol{T}_{D}=\left[\begin{array}{ccccc}
t_{D}^{11} & \cdots & t_{D}^{1 j} & \cdots & t_{D}^{1 m} \\
\vdots & & \vdots & & \vdots \\
t_{D}^{i 1} & \cdots & t_{D}^{i j} & \cdots & t_{D}^{i m} \\
\vdots & & \vdots & & \vdots \\
t_{D}^{m 1} & \cdots & t_{D}^{m j} & \cdots & t_{D}^{m m}
\end{array}\right]_{m \times m} \\
T_{D}^{\alpha}=\left[\begin{array}{ccccccc}
t_{D}^{11} / d_{1} & \cdots & t_{D}^{1 j} / d_{1} & \cdots & t_{D}^{1 m} / d_{1} \\
\vdots & & \vdots & & \vdots \\
t_{D}^{i 1} / d_{i} & \cdots & t_{D}^{i j} / d_{i} & \cdots & t_{D}^{i m} / d_{i} \\
\vdots & & \vdots & & \vdots \\
t_{D}^{m 1} / d_{m} & \cdots & t_{D}^{m j} / d_{m} & \cdots & t_{D}^{m m} / d_{m}
\end{array}\right]=\left[\begin{array}{ccccc}
t_{D}^{\alpha 11} & \cdots & t_{D}^{\alpha 1 j} & \cdots & t_{D}^{\alpha 1 m} \\
\vdots & & \vdots & & \vdots \\
t_{D}^{\alpha i 1} & \cdots & t_{D}^{\alpha i j} & \cdots & t_{D}^{\alpha i m} \\
\vdots & & \vdots & & \vdots \\
t_{D}^{\alpha m 1} & \cdots & t_{D}^{\alpha m j} & \cdots & t_{D}^{\alpha m m}
\end{array}\right]_{m \times m}
\end{gathered}
$$

Step 9 Calculate the raw influential weights of a DANP model. The adjusted super-matrix should multiply the normalized dimensional influence relation matrix $T_{D}^{\alpha}$ by the un-weighted super-matrix $W$, and the limiting super-matrix can be derived from multiplying by itself multiple times until the weights become converged as a weighted super-matrix (i.e., $\left.\boldsymbol{W}^{N}=\boldsymbol{T}_{D}^{\alpha} \boldsymbol{W}\right)$. The raw influential weight $w_{i}$ of each criterion $(i=1,2, \ldots, n)$ can thus be calculated by $\lim _{z \rightarrow \infty}\left(\boldsymbol{W}^{N}\right)^{z}$ (i.e., the raw influential weights $\boldsymbol{w}=\left(w_{1}, \ldots, w_{i}, \ldots, w_{n}\right)$ ).

Step 10 Adjust the influential weight of each criterion (attribute) based on a DM's emphasis on the dual financial objectives. Since the attributes in the DANP model come from the union of the two CORE sets (i.e., $\mathrm{CORE}_{\text {Gross }}$ and $C O R E_{\text {Net }}$ ), some attributes would only appear in one of the CORE set, and some others would be in both of the CORE sets. Therefore, the influential raw weight of the $i$ th attribute from DANP weights could be further adjusted as $w_{A d j_{i}}$ for $i=1,2, \ldots, n$ in Equation (8). 


$$
w_{A d j_{i}}=\lambda \times w_{i}^{\text {Gross }}+(1-\lambda) \times w_{i}^{\text {Net }}=w_{i}^{r a w}
$$

In Equation (7), $\lambda$ denotes a DM's emphasis on the gross profit objective, and $(1-\lambda)$ denotes the emphasis on the net profit objective. If the $i$ th attribute was only included in CORE $E_{\text {Gross }}$, then $w_{i}^{\text {Gross }}$ equals the influential raw weight of $w_{i}$ (i.e., $w_{i}^{\text {raw }}$ ) in Step 9, and $w_{i}^{\text {net }}=0$. If the $i$ th attribute was included in both $\mathrm{CORE}_{\mathrm{Gross}}$ and CORE $\mathrm{Net}$, then $w_{i}^{\text {raw }}=\lambda \times w_{i}^{\text {Gross }}+(1-\lambda) \times w_{i}^{\text {Net }}=w_{\text {Adj }_{i}}$, termed as $\lambda$-adjustment. Thus, the adjusted influential weight of each attribute can be normalized (sum up to one) as the adjusted DANP weight (i.e., $w_{a d j}^{N}$ ) considering the dual financial objectives.

\subsection{Improvement Planning by the Modified VIKOR}

By Step 10, the required influential weight of each attribute (after adjustment) based on a DM's self-defined emphasis on the dual financial objectives can be obtained. In the next, the modified VIKOR method not only can rank objects (or called alternatives) but also has strength in supporting companies for improvement planning-by identifying its priority gaps_towards excellence. The original idea of VIKOR begins with an $L_{k}^{H}$-metric as Equation (9), in which, m objectives can be expressed as $\mathrm{O}_{1}, \mathrm{O}_{2}$, $\ldots, \mathrm{O}_{\mathrm{m}}$; the performance score on the $i$ th attribute is denoted as $p_{k i}$ for the object $\mathrm{k}$, and $w_{A d j_{i}}^{N}$ is the adjusted (after normalization) influential weight of the $i$ th attribute for object $k(i=1,2, \ldots, n)$.

$$
L_{k}^{H}=\left\{\sum_{i=1}^{n}\left[w_{A d j_{i}}^{N}\left(\left|p_{i}^{*}-p_{k i}\right|\right) /\left(p_{i}^{*}-p_{i}^{-}\right)\right]^{H}\right\}^{\frac{1}{H}}, 1 \leq H \leq \infty ; i=1, \ldots, n
$$

Then, while $H=1$ and $H=\infty$, the indices $S_{k}$ and $R_{k}$ for object $\mathrm{k}$ can be calculated as Equations (10) and (11).

$$
\begin{gathered}
S_{k}=L_{k}^{H=1}=\sum_{i=1}^{n}\left[w_{A d j_{i}}^{N}\left(\left|p_{j}^{*}-p_{k j}\right|\right) /\left(\left|p_{j}^{*}-p_{j}^{-}\right|\right)\right] \\
R_{k}=L_{k}^{H=\infty}=\max _{i}\left\{w_{A d j_{i}}^{N}\left(\left|p_{i}^{*}-p_{k i}\right|\right) /\left(\left|p_{i}^{*}-p_{i}^{-}\right|\right) \mid i=1,2, \ldots, n\right\}
\end{gathered}
$$

The modified VIKOR enhances the settings of the classical VIKOR (in the classical approach, $p_{i}^{*}=\max _{k} p_{k i}$ and $p_{i}^{-}=\min _{k} p_{k i}$ ); in the modified VIKOR, $p_{i}^{\text {aspire }}$ (replace $p_{i}^{*}$ ) denotes the best/ideal value on the $i$ th attribute and $p_{i}^{\text {worst }}$ (replace $p_{i}^{-}$) the worst value on the $i$ th attribute [29]. For example, if the score on each attribute for all the objects were collected from questionnaires, and it ranged from 0 to 10 (Worst performance $\leftarrow 0,1,2, . ., 5, \ldots, 9,10 \rightarrow$ Best performance), then the aspired level and the worst value can be set as $p_{i}^{\text {aspire }}=10$ and $p_{i}^{\text {worst }}=0$ for each attribute. This modified approach may indicate an object's performance gap —use the aspired level as its target-on each attribute.

In Equations (10) and (11), if $p_{i}^{*}$ was replaced by $p_{i}^{\text {aspire }}$ and $p_{i}^{-}$was replaced by $p_{i}^{\text {worst }}$, the obtained $S_{k}$ and $R_{k}$ can be synthesized as a new ranking index $Q_{k}$ based on the weighted average opinions (i.e., weight $=v$ ) and the individual regret (i.e., weight $=1-v$ ) in Equation (12) to modify the classical VIKOR method.

$$
Q_{k}=v \times S_{k}+(1-v) \times R_{k}
$$

Step 11 Obtain each object's performance scores on the attributes that are under evaluation, and calculate the performance gap for each object on each attribute for identifying the priority gap. The obtained priority gap can be applied as a guidance for a systematic improvement.

The required steps and the involved soft computing and MCDM methods are summarized in Figure 2, which shows to apply the proposed approach to reach the long-term business sustainability through continuous improvement. 


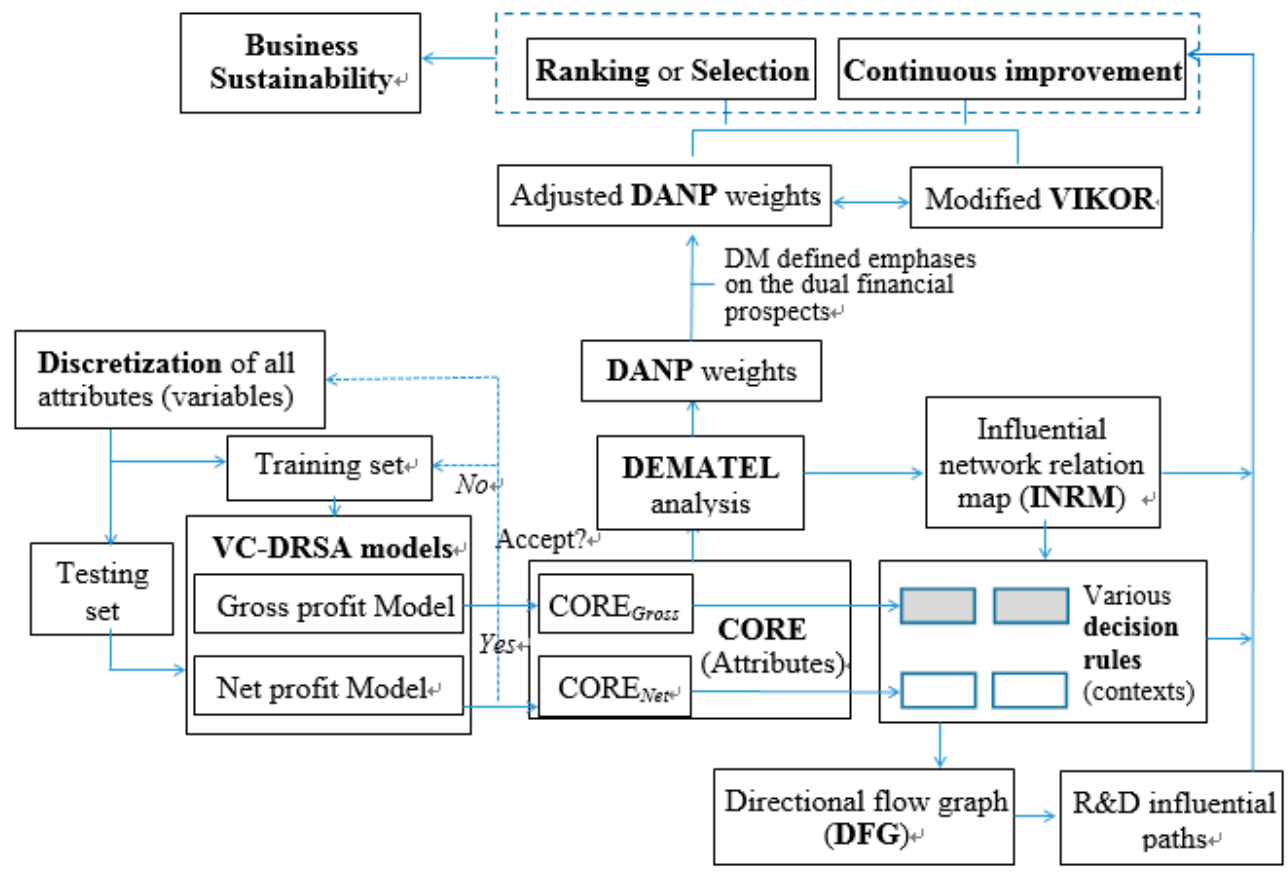

Figure 2. Illustration of the research framework.

\section{Empirical Case Analysis and Discussions}

Considering the complicated relationship between R\&D and future FP, an understandable guidance for companies to improve its performance would provide high business value in practice. Therefore, this study adopted the semiconductor industry in Taiwan as a case study, to illustrate how to form a hybrid decision model to reach this goal.

\subsection{Data for VC-DRSA Model}

For the availability and the consistency of data sources, this study adopted all the semiconductor companies listed on the Taiwan stock market to retrieve the patterns of FP changes, considering the effect of R\&D. The covered period spanned from 2006 to 2013. Since the effect of R\&D would take time to reveal its influence, a 2-year moving time window was used for setting the condition attributes and the corresponding decision attribute (as different DCs) in the VC-DRSA model.

Take the data laid down in the first period, for example, the averaged results of condition attributes (includes financial and R\&D attributes) in 2006 and 2007 were matched with the associated average results in 2008 and 2009 of decision attribute (FP measurement). The remaining two data sets in the following periods were organized in the same approach, and Figure 3 illustrates the framework of the 2-year moving average time windows from 2006 to 2013 (three sets of data); there were total 105 objects (observations) collected during this period.

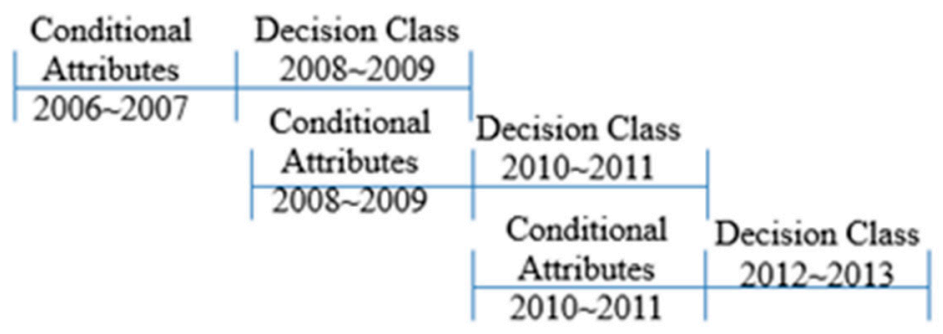

Figure 3. Moving time window of the research model. 
The condition attributes comprised of two parts: the financial and the R\&D ones. There were total 16 condition attributes included for modeling: 14 commonly used financial ratios (from four dimensions, categorized by the authority of stock market in Taiwan) and two R\&D attributes. Since two financial objectives will lead to two different VC-DRSA models, the initially involved number of attributes exceed 30 . The adopted attributes and the corresponding symbols are summarized in Table 1.

Table 1. Condition and decision attributes for VC-DRSA.

\begin{tabular}{|c|c|c|c|}
\hline \multirow{3}{*}{ Financial Objectives } & Decision Attributes & Symbols & Definitions \\
\hline & Gross profit & GrossProfit & (revenue- cost)/total revenue \\
\hline & Net profit & NetProfit & (revenue- cost-expense)/total revenue \\
\hline Dimensions & Condition Attributes & Symbols & Brief explanations \\
\hline \multirow{2}{*}{ Capital Structure } & Debt to total asset & Debt & $\begin{array}{l}\text { Higher debt to asset ratio often increases the } \\
\text { financial risk }\end{array}$ \\
\hline & Long-term capital to total asset & LongCap & $\begin{array}{l}\text { Higher long-term capital ratio is beneficial for a } \\
\text { company's financial stability }\end{array}$ \\
\hline \multirow{3}{*}{ Payback Capability } & Liquidity ratio & Liquidity & Higher liquidity implies better payback capability \\
\hline & Quick ratio & Quick & Similar effect as the liquidity ratio \\
\hline & Interest coverage ratio & IntCov & $\begin{array}{l}\text { Higher interest coverage ratio decrease the } \\
\text { financial risk }\end{array}$ \\
\hline \multirow{6}{*}{ Operational Efficiency } & Accounts receivable & AR_turnover & Higher $A R \_$turnover implies superior efficiency \\
\hline & Days for collecting AR & AR_days & Shorter AR_days implies superior efficiency \\
\hline & Inventory turnover & InvTurnover & Higher InvTurnover implies superior efficiency \\
\hline & Average days sales of inventory & $D A Y_{S}$ & Shorter $D A Y_{s}$ implies superior efficiency \\
\hline & Fixed asset turnover & FAssetTurn & Higher FAssetTurn implies superior efficiency \\
\hline & Asset turnover & AssetTurnover & Similar effect as FAssetTurn \\
\hline \multirow{3}{*}{ Cash Flow } & Operating cash-flow ratio & CashFlow & $\begin{array}{l}\text { CashFlow is a measure of how well current } \\
\text { liabilities are covered by the cash flow generated } \\
\text { from operations }\end{array}$ \\
\hline & Cash-flow adequacy ratio & CashFlow_adq & $\begin{array}{l}\text { It measures how well a company can cover its } \\
\text { payments of long-term debt by the cash flow } \\
\text { generated from operations }\end{array}$ \\
\hline & Cash-flow reinvestment ratio & CashFlow_reinv & $\begin{array}{l}\text { It measures the amount of cash flow that a } \\
\text { company is routinely investing back into itself }\end{array}$ \\
\hline \multirow[t]{2}{*}{$R \mathcal{E} D$} & $R \& D$ expense ratio & $R D \_\exp$ & $\begin{array}{l}\text { It measures a firm's R\&D expenses to its annual } \\
\text { revenue }\end{array}$ \\
\hline & Patent number & Patent & Annual patent number \\
\hline
\end{tabular}

The data for all the financial attributes and one R\&D attribute (i.e., $R \& D$ expenditure ratio) were collected from Taiwan Economic Journal (TEJ) database [42]; the remaining R\&D attribute-Patent (acquired number of patents in a year)—was retrieved from the Ministry of Science and Technology in Taiwan, where only the patents issued by the United States Patent and Trademark Office were counted). The decision attribute was defined by using the gross or the net profit ratio in the subsequent time frame, to explore the associated antecedents/premises of Good FP prospect under each kind of financial objective (in two VC-DRSA models).

\subsection{VC-DRSA for Identifying CORE Attributes and Decision Rules}

As the effect of R\&D on the gross and the net profitability would not be the same, VC-DRSA algorithm was conducted under these two profitability objectives separately. Data pre-processing was conducted, for DMs to get intuitive understandings from the obtained decision rules. Two commonly applied methods were used: the one-third and the normal-distribution based discretization methods. The one-third method discretized the decision attribute in three states by ranking it from high to low in each time frame, and the top $1 / 3$, the middle $1 / 3$, and the bottom $1 / 3$ alternatives were 
classified as Good, Neutral, and Bad. For comparison, the other discretization method based on normal-distribution was also conducted. And the objects above $\bar{x}+(0.25 \times \mathrm{SD})$, the objects between $\bar{x} \pm(0.25 \times \mathrm{SD})$, and the objects below $\bar{x}-(0.25 \times \mathrm{SD})$ were classified as the aforementioned three states. Similarly, the condition attributes were also discretized in three states (i.e., high (H), middle $(\mathrm{M})$, and low $(\mathrm{L}))$ in each time frame by the aforementioned two discretization methods.

The jMAF [41] was adopted as the VC-DRSA classifier; the other two classifiers-decision tree (DT) and support vector machine (SVM)—-were also conducted for comparison, by using the DTREG [43]. A 5-fold cross-validation was repeated five times for each classifier, and VC-DRSA was examined by setting several consistency levels (CLs). Classification accuracy (CA) was used to indicate the approximation accuracy of these experiments, which calculated the correctly classified objects divided by all objects in the training set. The results of CA in various classifiers are summarized in Table 2 (the gross profit objective) and Table 3 (the net profit goal); in those two tables, VC-DRSA (CL $=0.95$, with one-third discretization) all revealed the highest $C A$ in average with acceptable results. Thus, the VC-DRSA $(C L=0.95)$ classifier was adopted to induce the CORE attributes and decision rules for each type of FP objective.

Table 2. Classification accuracy of various classifiers (Gross profit objective) (unit: \%).

\begin{tabular}{|c|c|c|c|c|c|c|c|c|c|c|c|c|}
\hline \multirow[b]{2}{*}{ Times } & \multicolumn{2}{|c|}{$\begin{array}{l}\text { VC-DRSA } \\
(C L=1.00)\end{array}$} & \multicolumn{2}{|c|}{$\begin{array}{l}\text { VC-DRSA } \\
(C L=0.95)\end{array}$} & \multicolumn{2}{|c|}{$\begin{array}{l}\text { VC-DRSA } \\
(C L=0.90)\end{array}$} & \multicolumn{2}{|c|}{$\begin{array}{l}\text { VC-DRSA } \\
(C L=0.85)\end{array}$} & \multicolumn{2}{|c|}{$\begin{array}{c}\text { SVM } \\
\text { (RBF-Kernel) }\end{array}$} & \multicolumn{2}{|c|}{ DT } \\
\hline & * 1-3rd & * Norm & $1-3 \mathrm{rd}$ & Norm & $1-3 r d$ & Norm & $1-3 \mathrm{rd}$ & Norm & $1-3 \mathrm{rd}$ & Norm & $1-3 r d$ & Norm \\
\hline 1 & 72.38 & 63.81 & 69.52 & 69.62 & 64.76 & 63.81 & 67.62 & 63.81 & 61.33 & 61.65 & 61.63 & 62.24 \\
\hline 2 & 68.57 & 65.71 & 71.43 & 66.67 & 67.62 & 65.71 & 66.67 & 63.81 & 61.47 & 60.24 & 64.13 & 61.47 \\
\hline 3 & 69.52 & 65.71 & 72.38 & 69.52 & 65.71 & 63.81 & 68.57 & 65.71 & 64.62 & 59.17 & 63.81 & 60.24 \\
\hline 4 & 69.52 & 66.67 & 73.33 & 67.62 & 66.67 & 64.76 & 63.81 & 64.62 & 62.02 & 57.39 & 60.24 & 61.63 \\
\hline 5 & 67.62 & 67.62 & 70.48 & 68.57 & 66.67 & 64.62 & 67.62 & 63.81 & 61.24 & 62.02 & 62.16 & 59.38 \\
\hline Average & 69.52 & 65.90 & 71.43 & 68.40 & 66.29 & 64.54 & 66.86 & 64.35 & 62.14 & 60.09 & 62.39 & 60.99 \\
\hline SD & 1.78 & 1.41 & 1.51 & 1.26 & 1.09 & 0.79 & 1.83 & 0.84 & 1.42 & 1.89 & 1.60 & 1.16 \\
\hline
\end{tabular}

Table 3. Classification accuracy of various classifiers (Net profit objective) (unit: \%).

\begin{tabular}{|c|c|c|c|c|c|c|c|c|c|c|c|c|}
\hline \multirow[b]{2}{*}{ Times } & \multicolumn{2}{|c|}{$\begin{array}{l}\text { VC-DRSA } \\
(C L=1.00)\end{array}$} & \multicolumn{2}{|c|}{$\begin{array}{r}\text { VC-DRSA } \\
(C L=0.95)\end{array}$} & \multicolumn{2}{|c|}{$\begin{array}{l}\text { VC-DRSA } \\
(C L=0.90)\end{array}$} & \multicolumn{2}{|c|}{$\begin{array}{r}\text { VC-DRSA } \\
(C L=0.85)\end{array}$} & \multicolumn{2}{|c|}{$\begin{array}{c}\text { SVM } \\
\text { (RBF-Kernel) }\end{array}$} & \multicolumn{2}{|c|}{ DT } \\
\hline & * $1-3 \mathrm{rd}$ & * Norm & $1-3 \mathrm{rd}$ & Norm & $1-3 r d$ & Norm & $1-3 \mathrm{rd}$ & Norm & $1-3 \mathrm{rd}$ & Norm & $1-3 r d$ & Norm \\
\hline 1 & 74.29 & 70.48 & 75.24 & 71.43 & 71.43 & 68.57 & 70.48 & 66.67 & 67.71 & 63.81 & 64.62 & 58.10 \\
\hline 2 & 73.33 & 69.52 & 77.14 & 70.48 & 71.43 & 68.57 & 68.57 & 67.62 & 65.71 & 62.16 & 63.81 & 62.12 \\
\hline 3 & 70.48 & 69.52 & 77.14 & 73.33 & 71.43 & 69.52 & 70.48 & 71.43 & 63.81 & 61.63 & 62.16 & 63.81 \\
\hline 4 & 73.33 & 67.62 & 75.24 & 73.33 & 72.38 & 67.62 & 71.43 & 64.76 & 66.67 & 62.02 & 61.63 & 62.16 \\
\hline 5 & 74.29 & 70.48 & 79.05 & 71.43 & 73.33 & 69.52 & 69.52 & 68.57 & 67.62 & 64.62 & 64.54 & 63.81 \\
\hline Average & 73.14 & 69.52 & 76.76 & 72.00 & 72.00 & 68.76 & 70.10 & 67.81 & 66.30 & 62.85 & 63.35 & 62.00 \\
\hline SD & 1.56 & 1.17 & 1.59 & 1.27 & 0.85 & 0.79 & 1.09 & 2.47 & 1.61 & 1.29 & 1.38 & 2.33 \\
\hline
\end{tabular}

In Tables 2 and 3, SD denotes standard deviation. The co-shared attributes and the distinct attributes of each type of FP objective are summarized in Table 4; the union of the two CORE sets comprises of 14 attributes, those attributes were further analyzed by the DEMATEL technique. Also, the strong decision rules (i.e., with high supports) associated with the two types of profitability prospects are shown in Table 5.

In Table 5, the top two strong decision rules of each model (i.e., the gross or net profit objective) are shown with the number of supports. It can be observed that the $R D \_$exp attribute appeared in both models, which suggests the importance of R\&D investment in reaching better financial prospects. 
Table 4. CORE attributes by the two types of FP objectives.

\begin{tabular}{clc}
\hline FP Objectives & \multicolumn{1}{c}{ CORE Attributes } & Numbers \\
\hline Gross profit & LongCap, Liquidity, AR_days, AssetTurnover, CF, CF_reinv, RD_exp & 7 \\
\hline \multirow{2}{*}{ Net profit } & $\begin{array}{l}\text { Debt, LongCap, Quick, IntCov, Inventory, FAssetTurn, AssetTurnover, CF, } \\
\text { CF_adq,CF_reinv, RD_exp, Patents }\end{array}$ & 12 \\
\hline
\end{tabular}

Note: The union of the two sets of CORE attributes comprised of 14 attributes.

Table 5. Strong decision rules of the two types of FP objectives (DC $\geq$ Good).

\begin{tabular}{clc}
\hline FP Objectives & \multicolumn{1}{c}{ Decision Rules } & Supports \\
\hline \multirow{2}{*}{ Gross profit } & LongCap $\geq \mathrm{M} \& A s s e t$ Turnover $\geq \mathrm{M} \& R D \_e x p \geq \mathrm{H}$ & 16 \\
& LongCap $\geq \mathrm{H} \& R D \_$_exp $\geq \mathrm{H}$ & 14 \\
\hline \multirow{2}{*}{ Net profit } & $C F \geq \mathrm{H} \& C F \_a d q \geq \mathrm{H} \& C F \_r e i n v \geq \mathrm{H}$ & 7 \\
& Liquidity $\geq \mathrm{H} \& C F \_r e i n v \geq \mathrm{H} \& R D \_$exp $\geq \mathrm{H}$ & 6 \\
\hline
\end{tabular}

\subsection{Adjusted DANP (DEMATEL-Based ANP) Influential Weights}

In the previous subsection, Table 4 indicates the CORE attributes from the two types of objectives (i.e., gross and net profitability). CORE attributes denote the minimal and indispensable attributes for a VC-DRSA model to classify objects without decreasing its approximation accuracy. Therefore, the union of the two sets of CORE attributes in Table 4 were further analysed by DANP, combined into a single decision model by $\lambda$-adjustment (Step 10), for obtaining the DANP influential weights.

The opinions for the calculations of DANP were collected from domain experts (eight experts) in the financial or information technology industry; all of them have working experience in these domains for more than 15 years, and three of the experts are working in semiconductor companies. Their job titles include Chief Financial Officer (CFO), Director of R\&D, Manager, Senior Analyst, Senior Consultant, and Fund Manager. The calculation details of DEMATEL and DANP can be found in Appendix A. The analysis from DEMATEL may divide dimensions/attribute into a cause group, and an effect group, the directional influences among dimensions (INRM) are shown in Figure 4. The influences among dimensions and attributes are shown in Tables 6 and 7 (from Table A4 in Appendix A).

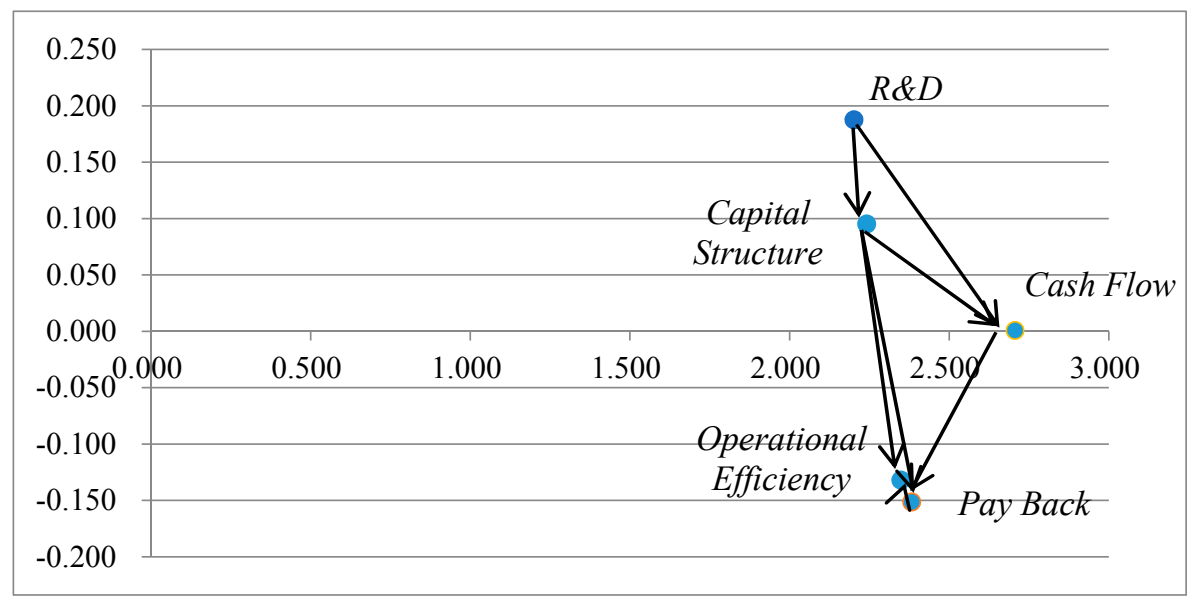

Figure 4. Internetwork relationship map (INRM) of dimensions. 
Table 6. Directional influences among dimensions (DEMATEL analysis).

\begin{tabular}{rcccc}
\hline Dimensions & $r_{\boldsymbol{i}}^{\boldsymbol{D}}$ & $\boldsymbol{s}_{\boldsymbol{i}}^{\boldsymbol{D}}$ & $\boldsymbol{s}_{\boldsymbol{i}}^{\boldsymbol{D}}-\boldsymbol{d}_{\boldsymbol{i}}^{\boldsymbol{D}}$ & $\boldsymbol{r}_{\boldsymbol{i}}^{\boldsymbol{D}}+\boldsymbol{s}_{\boldsymbol{i}}^{\boldsymbol{D}}$ \\
\hline Capital Structure $\left(D_{1}\right)$ & 1.168 & 1.073 & 0.095 & 2.242 \\
Pay Back $\left(D_{2}\right)$ & 1.116 & 1.267 & -0.151 & 2.383 \\
Operational Efficiency $\left(D_{3}\right)$ & 1.108 & 1.240 & -0.132 & 2.349 \\
Cash Flow $\left(D_{4}\right)$ & 1.353 & 1.353 & 0.001 & 2.706 \\
RED $\left(D_{5}\right)$ & 1.195 & 1.007 & 0.188 & 2.202 \\
\hline
\end{tabular}

Table 7. Directional influences among condition attributes (by DEMATEL).

\begin{tabular}{rcccc}
\hline Attributes & $\boldsymbol{r}_{\boldsymbol{i}}^{\boldsymbol{A}}$ & $\boldsymbol{s}_{\boldsymbol{i}}^{\boldsymbol{A}}$ & $\boldsymbol{r}_{\boldsymbol{i}}^{\boldsymbol{A}}-\boldsymbol{s}_{\boldsymbol{i}}^{\boldsymbol{A}}$ & $\boldsymbol{r}_{\boldsymbol{i}}^{\boldsymbol{A}}+\boldsymbol{s}_{\boldsymbol{i}}^{\boldsymbol{A}}$ \\
\hline Debt $\left(A_{1}\right)$ & 3.120 & 2.801 & 0.318 & 3.438 \\
LongCap $\left(A_{2}\right)$ & 3.542 & 3.223 & 0.319 & 3.861 \\
Liquidity $\left(A_{3}\right)$ & 3.548 & 3.851 & -0.302 & 3.246 \\
Quick $\left(A_{4}\right)$ & 3.301 & 3.333 & -0.033 & 3.268 \\
IntCov $\left(A_{5}\right)$ & 2.711 & 3.419 & -0.707 & 2.004 \\
AR_days $\left(A_{6}\right)$ & 3.652 & 2.881 & 0.771 & 4.423 \\
Inventory $\left(A_{7}\right)$ & 3.679 & 3.532 & 0.147 & 3.826 \\
FixAssetTurn $\left(A_{8}\right)$ & 2.325 & 3.185 & -0.859 & 1.466 \\
AssetTurnover $\left(A_{9}\right)$ & 3.052 & 4.186 & -1.133 & 1.919 \\
CF $\left(A_{10}\right)$ & 4.138 & 4.228 & -0.090 & 4.048 \\
CF_adq $\left(A_{11}\right)$ & 3.320 & 3.421 & -0.101 & 3.219 \\
CF_reinv $\left(A_{12}\right)$ & 4.041 & 3.683 & 0.358 & 4.399 \\
RD_exp $\left(A_{13}\right)$ & 4.282 & 3.857 & 0.424 & 4.706 \\
Patent $\left(A_{14}\right)$ & 2.625 & 1.737 & 0.888 & 3.514 \\
\hline
\end{tabular}

The raw weights of DANP are listed in Table 8; besides, DM may adjust the final weights based on his emphasis on the gross and the net profit objectives. In this case, the relative emphasis on the gross and the net profit objectives was assumed to be 0.4 and 0.6 (i.e., put $40 \%$ weight on the gross and $60 \%$ on the net profit objectives) respectively; the adjusted weights from DANP are also shown in Table 8.

Figure 4 (INRM) only indicates the directional influence among the five dimensions; the influence within each dimension (i.e., directional influence among attributes in each dimension) could be referred to $r_{i}^{A}-s_{i}^{A}$ in Table 7. This figure shows R\&D dimension has the highest influence on the other aspects, which affirms the importance of R\&D efforts for the semiconductor industry.

\subsection{Synthesized Performance Gaps by Modified VIKOR}

To illustrate the proposed approach for guiding improvements, the data (the averaged financial and R\&D indicators in 2011 and 2012) from four semiconductor companies were adopted, namely: $(A)$ Siliconware Precision Industries (code: 2325); (B) VIA Technologies (code: 2388); (C) MediaTek (code: 2454); (D) ADATA Technology (code: 3260). All of the training data were used to transform the four companies' raw indicators (e.g., Liquidity) into performance scores, range from 0 (the worst) to 10 (the best).

A percentile transformation method was conducted; for example, if a company's CF (cash flow) ratio ranked among the top $10 \%$ of the 35 companies, then the company's performance score on the CF attribute would be nine. By setting $v=0.8$ and 0.5 (refer Section 3.4), the modified VIKOR and the simple additive weighting (SAW) methods all revealed the same ranking result: $C \succ A \succ D \succ B$, which was consistent with their averaged FP in 2013 and $2014(0.4 \times$ Gross profit ratio $+0.6 \times$ Net profit ratio). The raw and adjusted weights of attributes by the DANP method is shown in Table 8 .

The ranking result, by the two aggregation methods (SAW and modified VIKOR), is shown in Table 9. If we extend the time-period to 2016, the four years' averaged FP result with the same weighing on the gross and net profit (i.e., $0.4 \times$ Gross profit ratio $+0.6 \times$ Net profit ratio), the top two are still the 
same, but the last two reverse (i.e., $C \succ A \succ B \succ D$ ). The actual averaged gross and net profit ratios in different period for each company are organized in Table 10. Although some minor inconsistency exists in the longer term (2013 2016), the model has shown its effectiveness for decision aids.

This study attempts to explore the complex/imprecise relationships among R\&D, financial attributes, and the FP objectives of semiconductor companies. Also, a hybrid MCDM model was proposed to evaluate a company's performance gaps-based on DMs' emphasis on the dual profitability objectives respectively-for improvement planning. Take company $A$ for example, and we may learn that its priority performance gaps would be different while the emphasis on the gross and the net profit objectives varied (refer Table 11).

Table 8. Raw and adjusted weights of attributes by DANP.

\begin{tabular}{rcccc}
\hline Attributes & Raw Weights & $\lambda$-Adjustment $(\boldsymbol{\lambda}$-adj) & Raw Weight $\times \boldsymbol{\lambda}$-adj & Adjusted Weights * \\
\hline Debt $\left(A_{1}\right)$ & 0.09 & 0.6 & 0.05 & 0.07 \\
LongCap $\left(A_{2}\right)$ & 0.10 & $(0.4+0.6)$ & 0.10 & 0.13 \\
Liquidity $\left(A_{3}\right)$ & 0.08 & 0.4 & 0.03 & 0.04 \\
Quick $\left(A_{4}\right)$ & 0.07 & 0.6 & 0.04 & 0.05 \\
IntCov $\left(A_{5}\right)$ & 0.07 & 0.6 & 0.04 & 0.05 \\
AR_days $\left(A_{6}\right)$ & 0.05 & 0.4 & 0.02 & 0.03 \\
Inventory $\left(A_{7}\right)$ & 0.06 & 0.6 & 0.04 & 0.05 \\
FixAssetTurn $\left(A_{8}\right)$ & 0.05 & 0.6 & 0.03 & 0.04 \\
AssetTurnover $\left(A_{9}\right)$ & 0.07 & $(0.4+0.6)$ & 0.07 & 0.09 \\
CF $\left(A_{10}\right)$ & 0.09 & $(0.4+0.6)$ & 0.09 & 0.11 \\
CF_adq $\left(A_{11}\right)$ & 0.07 & 0.6 & 0.08 & 0.05 \\
CF_reinv $\left(A_{12}\right)$ & 0.08 & $(0.4+0.6)$ & 0.12 & 0.10 \\
RD_exp $\left(A_{13}\right)$ & 0.12 & $(0.4+0.6)$ & 0.04 & 0.15 \\
Patent $\left(A_{14}\right)$ & 0.06 & 0.6 & 0.05 \\
\hline
\end{tabular}

Note: * Adjusted weights are the normalized results $w_{a d j}^{N}$; The attribute LongCap $\left(A_{2}\right)$ was included in both sets of the CORE attributes; its emphasis is $(0.4+0.6)$.

Table 9. Ranking results of the empirical case by the modified VIKOR and SAW.

\begin{tabular}{|c|c|c|c|c|c|c|c|c|c|c|}
\hline \multirow{2}{*}{ Criteria } & \multirow{2}{*}{$w_{a d j}^{N}$} & \multicolumn{4}{|c|}{ Companies (Performance Scores) } & & \multicolumn{4}{|c|}{ Companies (Performance Gaps) } \\
\hline & & $A$ & $B$ & $C$ & $D$ & & $A$ & $B$ & C & $D$ \\
\hline $\operatorname{Debt}\left(A_{1}\right)$ & 0.07 & 6 & 6 & 8 & 2 & & 0.4 & 0.4 & 0.2 & 0.8 \\
\hline LongCap $\left(A_{2}\right)$ & 0.13 & 3 & 6 & 9 & 7 & & 0.7 & 0.4 & 0.1 & 0.3 \\
\hline Liquidity $\left(A_{3}\right)$ & 0.04 & 5 & 7 & 8 & 5 & & 0.5 & 0.3 & 0.2 & 0.5 \\
\hline Quick $\left(A_{4}\right)$ & 0.05 & 6 & 8 & 9 & 4 & & 0.4 & 0.2 & 0.1 & 0.6 \\
\hline $\operatorname{Int} \operatorname{Cov}\left(A_{5}\right)$ & 0.05 & 7 & 1 & 9 & 4 & & 0.3 & 0.9 & 0.1 & 0.6 \\
\hline$A R \_$days $\left(A_{6}\right)$ & 0.03 & 4 & 8 & 8 & 8 & & 0.6 & 0.2 & 0.2 & 0.2 \\
\hline Inventory $\left(A_{7}\right)$ & 0.05 & 9 & 3 & 4 & 8 & & 0.1 & 0.7 & 0.6 & 0.2 \\
\hline FixAssetTurn $\left(A_{8}\right)$ & 0.04 & 4 & 5 & 9 & 9 & & 0.6 & 0.5 & 0.1 & 0.1 \\
\hline AssetTurnover $\left(A_{9}\right)$ & 0.09 & 6 & 2 & 5 & 9 & & 0.4 & 0.8 & 0.5 & 0.1 \\
\hline$C F\left(A_{10}\right)$ & 0.11 & 9 & 0 & 8 & 4 & & 0.1 & 1.0 & 0.2 & 0.6 \\
\hline CF_adq $\left(A_{11}\right)$ & 0.05 & 7 & 1 & 9 & 3 & & 0.3 & 0.9 & 0.1 & 0.7 \\
\hline$C F \_r e i n v\left(A_{12}\right)$ & 0.10 & 6 & 0 & 3 & 7 & & 0.4 & 1.0 & 0.7 & 0.3 \\
\hline$R D \_\exp \left(A_{13}\right)$ & 0.15 & 5 & 10 & 9 & 2 & & 0.5 & 0.0 & 0.1 & 0.8 \\
\hline \multirow{8}{*}{ Patent $\left(A_{14}\right)$} & 0.05 & 8 & 0 & 9 & 0 & & 0.2 & 1.0 & 0.1 & 1.0 \\
\hline & SAW * & 6.02 & 4.25 & 7.63 & 5.05 & VIKOR & & & & \\
\hline & Rank & (2) & (4) & (1) & (3) & $S_{\mathrm{i}}$ & 0.41 & 0.59 & 0.25 & 0.51 \\
\hline & & & & & & $R_{\mathrm{i}}$ & 0.7 & 1 & 0.7 & 1 \\
\hline & & & & & $Q_{\mathrm{i}}$ & $v=0.8$ & 0.47 & 0.67 & 0.34 & 0.60 \\
\hline & & & & & & (Rank) & (2) & (4) & $(1)$ & (3) \\
\hline & & & & & $Q_{\mathrm{i}}$ & $v=0.5$ & 0.55 & 0.79 & 0.47 & 0.70 \\
\hline & & & & & & (Rank) & (2) & (4) & (1) & (3) \\
\hline
\end{tabular}

Note: * In SAW method, the higher synthesized score the better the ranking result.

In Table 11, if company $A$ puts 0.4 (i.e., 40\%) emphasis on the gross profit and 0.6 (i.e., $60 \%$ ) emphasis on the net profit (i.e., put more emphasis on the net profit), the top three priority attributes for it to improve would be: $A_{2}$ (LongCap, the top priority), $A_{13}$ (RD_exp, the second priority), and $A_{12}$ 
(CF_reinv, the third priority). It is obvious that if company $A$ puts different emphasis on the two profit objectives (e.g., put $100 \%$ emphasis on the net profit objective), the adjusted and normalized weights would form a different weighting system (refer Step 10). As a result, the proposed hybrid MCDM model can support a company-based on its emphasis on the two FP objectives-to identify its improvement priority, which is the major novelty and contribution of the study.

Furthermore, incorporated with the previous findings (i.e., DEMATEL analysis and INRM), semiconductor companies may identify the cause-effect relationships of dimensions/attributes, along with the contexts of strong decision rules, to gain more insights by the combined DFG. Take the two strong decision rules in Table 5-associated with the net profit objective-for example, it may be integrated with the INRM to generate a DFG, which may indicate the influential paths of R\&D that may lead to "at least Good FP" in the next period. The DFG is shown in Figure 5.

Table 10. Averaged FP of the four companies in different time periods (Unit: \%).

\begin{tabular}{ccccc}
\hline & $\boldsymbol{A}$ & $\boldsymbol{B}$ & $\boldsymbol{C}$ & $\boldsymbol{D}$ \\
\hline * AvgGross 2013 2014 & 23.04 & 29.24 & 46.36 & 9.20 \\
AvgNet 2013 2014 & 11.32 & -22.76 & 20.99 & 4.36 \\
$(0.4 \mathrm{G}, 0.6 \mathrm{~N})$ 2013 2014 & $16.01 *$ & -1.96 & 31.14 & 6.29 \\
(Rank) & $(2)$ & $(4)$ & $(1)$ & $(3)$ \\
AvgGross 2013 2016 & 27.32 & 28.72 & 42.90 & 9.67 \\
AvgNet 2013 2016 & 11.22 & -5.86 & 15.70 & 3.53 \\
$(0.4 \mathrm{G}, 0.6 \mathrm{6N})$ 2013 2016 & 16.22 & 7.97 & 26.58 & 5.98 \\
(Rank) & $(2)$ & $(3)$ & $(1)$ & $(4)$
\end{tabular}

Note: * AvgGross 2013 2014 denotes the averaged gross profit of a company during 2013 to 2014; For example, $(0.4 \mathrm{G}, 0.6 \mathrm{~N}) 2013 \sim 2014$ for $A$ is calculated by: $16.01=(0.4 \times 23.04)+(0.6 \times 11.32)$.

Table 11. Gaps of $A$ while $40 \%$ on Gross and $60 \%$ on Net profit measures $(0.4 \mathrm{G}, 0.6 \mathrm{~N})$.

\begin{tabular}{ccccccccccccccc}
\hline Attributes & $A_{\mathbf{1}}$ & $\boldsymbol{A}_{\mathbf{2}}$ & $\boldsymbol{A}_{\mathbf{3}}$ & $\boldsymbol{A}_{\mathbf{4}}$ & $\boldsymbol{A}_{\mathbf{5}}$ & $\boldsymbol{A}_{\mathbf{6}}$ & $\boldsymbol{A}_{\mathbf{7}}$ & $\boldsymbol{A}_{\mathbf{8}}$ & $\boldsymbol{A}_{\mathbf{9}}$ & $\boldsymbol{A}_{\mathbf{1 0}}$ & $\boldsymbol{A}_{\mathbf{1 1}}$ & $\boldsymbol{A}_{\mathbf{1 2}}$ & $\boldsymbol{A}_{\mathbf{1 3}}$ & $\boldsymbol{A}_{\mathbf{1 4}}$ \\
\hline Gaps of $A$ & 0.40 & 0.70 & 0.50 & 0.40 & 0.30 & 0.60 & 0.10 & 0.60 & 0.40 & 0.10 & 0.30 & 0.40 & 0.50 & 0.20 \\
$\quad w_{\text {adj }}^{N}$ & 0.07 & 0.13 & 0.04 & 0.05 & 0.05 & 0.03 & 0.05 & 0.04 & 0.09 & 0.11 & 0.05 & 0.10 & 0.15 & 0.05 \\
* Weighted Gap (\%) & 2.80 & 9.10 & 2.00 & 2.00 & 1.50 & 1.80 & 0.50 & 2.40 & 3.60 & 1.10 & 1.50 & 4.00 & 7.50 & 1.00 \\
$\quad$ (Priority) & & $(1)$ & & & & & & & & & & $(3)$ & $(2)$ & \\
\hline
\end{tabular}

Note: * This weighted gaps of company $A$ were calculated to indicate its improvement priority.

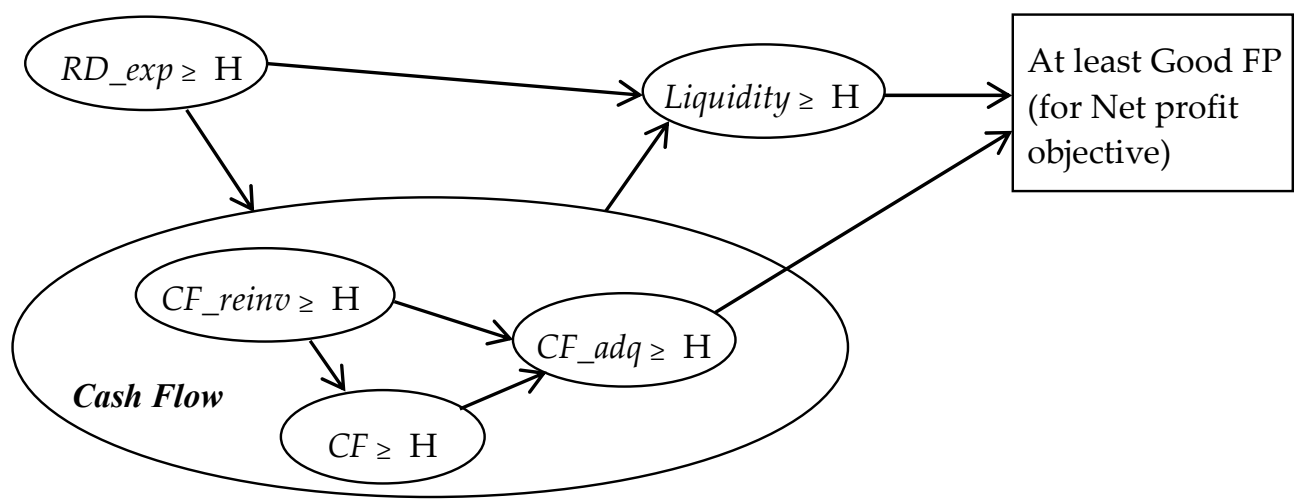

Figure 5. Direction flow graph (DFG) based on the strong rules for net profit objective.

According to Figure 5, semiconductor companies may learn that R\&D efforts should have a positive influence on the Cash Flow dimension, and thus lead to higher liquidity to reaching superior net profitability in the future. The combination of VC-DRSA decision rules with the INRM may generate various influential patterns, which could guide semiconductor companies to examine the likely effects of their R\&D investments for the net profit objective. 


\section{Discussions and Concluding Remarks}

This study has explored the influences of R\&D to reach the dual financial objectives of semiconductor companies to achieve business sustainability. The results indicate the existence of certain consistent patterns, which associate the influence of R\&D with several financial attributes to the dual profitability objectives. Besides, four listed semiconductor companies' R\&D and financial data were examined, and the ranking results of their FP are consistent with the four companies' actual FP from 2013 to 2014, which suggests the effectiveness of the proposed approach.

In practice, the research results and the proposed hybrid MCDM model incorporating domain experts' experience have delivered several implications to companies for their business applications:

(1) The critical role of R\&D investment for the FP and financial sustainability is confirmed, which echoes the findings in the previous research [3-6];

(2) The historical patterns revealed certain decision rules and the CORE attributes (Tables 4 and 5) to support companies' R\&D investment;

(3) The proposed model obtains the influential weight of each attribute (Table 8) for achieving ideal financial objectives;

(4) The proposed model supports a semiconductor company to identify its priority performance gaps for improvements (Table 11);

(5) The proposed model explores the influence patterns of $R \& D$ from the historical patterns in the form of decision rules and DFGs (Figure 5).

Compared with previous research, the importance of R\&D expenses is highlighted in this study and the outcomes can be referred to firms' investment decisions. The proposed approach further identifies the plausible R\&D influential paths that may lead to the dual profitability objectives. In other words, semiconductor companies may learn that R\&D investments are crucial to the FP, but not all $R \& D$ efforts may lead to satisfactory outcome. Take Figure 5 for example, to reach good FP on the net profitability, R\&D expenses should have positive influence to the cash flow dimension, and increase the liquidity of a company's short-term assets. Based on the findings above, semiconductor companies should examine its $R \& D$ projects, to see if its R\&D investments may cause the plausible effects to match those influential patterns (i.e., decision rules or DFGs).

This finding underscores the linkage between $R \& D$ efforts and the associated cash flow from operations, which should be aware by semiconductor companies. Furthermore, the case of company $A$ (in Section 4) shows how the hybrid model may identify a company's priority gaps, and contributes to improvement planning based on its emphasis on the dual objectives. The company $A$ is a world-leading IC design house, which also revealed outstanding FP records in the past several years. Nevertheless, its top three priority gaps (except $A_{1}$, which is mainly influenced by financial decisions) suggest that it should increase its R\&D expense $\left(A_{13}\right)$ from its operating cash flows, to reach a superior financial outcome in the next period. The findings above and implications are the two primary contributions of the present study.

Although this hybrid MCDM approach has shown its capability in identifying R\&D influences to the dual profitability objectives, the model still has several limitations. First, owing to the limited sample size, the collected knowledge-regarding the effect of each CORE attribute on the other ones-did not consider the differences in the sub-sectors (e.g., IC design, foundry, and packaging) among the semiconductor industry. Second, this study mainly includes the financial and R\&D factors for analysis, and future research may incorporate more dimensions (e.g., marketing or human resources) to enrich their findings. Despite the limitations, this study contributes to support semiconductor companies to improve their FP, which thus facilitates the understanding of the complex $R \& D$ influences in a real business environment. 
Acknowledgments: This study received financial subsidies from two grants; both came from the Ministry of Science and Technology (MOST) of Taiwan; the first one is under the grant numbers MOST-104-2410-H-305-052-MY3, and the second one is MOST-105-2410-H-034-019-MY2. The authors are grateful for those funding supports.

Author Contributions: K.Y. Shen mainly proposed and devised the hybrid MCDM model, and he prepared for the financial data collection, experiments, and writing of this study. M.R. Yan collected the patent information of those semiconductor companies, and he involved in the research design as well as the writing of partial contents and revisions. G.H. Tzeng examined the research framework and experiments of this study; he also guided the design of improvement planning mechanism of this work.

Conflicts of Interest: The authors declare no conflict of interest.

\section{Appendix A. (Calculation Details of DEMTEL and DANP)}

Refer to Step 4 to Step 9 in Sections 3.2 and 3.3 and Equations (1)-(7) for obtaining Tables A1-A7. Multiply the initial weighted super-matrix (Table A7) with itself several times (refer Step 9) until the stable raw weights were found.

Table A1. Initial average matrix $B$.

\begin{tabular}{cccccccccccccccc}
\hline & $\boldsymbol{A}_{\mathbf{1}}$ & $\boldsymbol{A}_{\mathbf{2}}$ & $\boldsymbol{A}_{\mathbf{3}}$ & $\boldsymbol{A}_{\mathbf{4}}$ & $\boldsymbol{A}_{\mathbf{5}}$ & $\boldsymbol{A}_{\mathbf{6}}$ & $\boldsymbol{A}_{\mathbf{7}}$ & $\boldsymbol{A}_{\mathbf{8}}$ & $\boldsymbol{A}_{\mathbf{9}}$ & $\boldsymbol{A}_{\mathbf{1 0}}$ & $\boldsymbol{A}_{\mathbf{1 1}}$ & $\boldsymbol{A}_{\mathbf{1 2}}$ & $\boldsymbol{A}_{\mathbf{1 3}}$ & $\boldsymbol{A}_{\mathbf{1 4}}$ & Sum \\
\hline $\boldsymbol{A}_{\mathbf{1}}$ & 0.00 & 3.00 & 2.00 & 2.13 & 2.88 & 2.13 & 3.00 & 1.13 & 1.88 & 1.25 & 1.13 & 2.00 & 1.25 & 0.63 & 24.38 \\
$\boldsymbol{A}_{\mathbf{2}}$ & 3.88 & 0.00 & 1.25 & 1.25 & 3.00 & 1.13 & 1.25 & 1.13 & 2.88 & 3.00 & 2.00 & 2.13 & 3.63 & 1.13 & 27.63 \\
$\boldsymbol{A}_{\mathbf{3}}$ & 2.25 & 1.13 & 0.00 & 2.88 & 1.00 & 1.13 & 2.13 & 3.00 & 3.50 & 3.38 & 2.00 & 2.00 & 2.88 & 0.50 & 27.75 \\
$\boldsymbol{A}_{\mathbf{4}}$ & 1.13 & 1.38 & 2.75 & 0.00 & 1.13 & 1.25 & 1.13 & 1.38 & 3.00 & 3.38 & 2.13 & 2.88 & 2.88 & 0.75 & 25.13 \\
$\boldsymbol{A}_{\mathbf{5}}$ & 2.00 & 1.13 & 2.00 & 2.00 & 0.00 & 1.25 & 2.00 & 2.00 & 1.88 & 1.13 & 1.25 & 1.13 & 2.88 & 0.38 & 21.00 \\
$\boldsymbol{A}_{\mathbf{6}}$ & 2.00 & 2.00 & 3.75 & 2.88 & 2.00 & 0.00 & 3.75 & 2.00 & 2.88 & 2.88 & 1.25 & 1.38 & 1.25 & 0.75 & 28.75 \\
$\boldsymbol{A}_{\mathbf{7}}$ & 1.25 & 1.13 & 3.00 & 1.13 & 2.88 & 3.50 & 0.00 & 2.00 & 2.75 & 3.50 & 2.88 & 3.13 & 1.13 & 0.50 & 28.75 \\
$\boldsymbol{A}_{\mathbf{8}}$ & 1.25 & 2.00 & 2.00 & 1.13 & 1.25 & 1.13 & 2.00 & 0.00 & 2.75 & 1.13 & 1.00 & 1.25 & 0.63 & 0.63 & 18.13 \\
$\boldsymbol{A}_{\mathbf{9}}$ & 1.25 & 2.00 & 2.00 & 1.88 & 1.25 & 2.00 & 2.13 & 2.00 & 0.00 & 2.75 & 1.88 & 1.50 & 2.13 & 0.75 & 23.50 \\
$\boldsymbol{A}_{\mathbf{1 0}}$ & 2.25 & 3.50 & 3.38 & 3.50 & 3.25 & 1.88 & 1.13 & 1.25 & 2.13 & 0.00 & 3.00 & 3.50 & 3.13 & 0.50 & 32.38 \\
$\boldsymbol{A}_{\mathbf{1 1}}$ & 1.00 & 3.00 & 1.38 & 1.38 & 1.13 & 1.13 & 2.00 & 1.13 & 2.00 & 3.00 & 0.00 & 3.75 & 3.13 & 1.00 & 25.00 \\
$\boldsymbol{A}_{\mathbf{1 2}}$ & 1.38 & 2.88 & 2.00 & 2.25 & 2.75 & 1.00 & 2.88 & 2.75 & 2.63 & 3.50 & 2.88 & 0.00 & 3.25 & 1.88 & 32.00 \\
$\boldsymbol{A}_{\mathbf{1 3}}$ & 1.13 & 1.13 & 3.00 & 2.25 & 2.88 & 2.88 & 2.88 & 3.13 & 3.00 & 2.88 & 3.00 & 2.75 & 0.00 & 3.75 & $34.63 *$ \\
$\boldsymbol{A}_{\mathbf{1 4}}$ & 1.00 & 0.63 & 1.88 & 1.00 & 1.38 & 2.25 & 2.00 & 1.88 & 2.00 & 1.25 & 2.13 & 1.13 & 2.00 & 0.00 & 20.50 \\
Sum & 21.76 & 24.88 & 30.38 & 25.63 & 26.75 & 22.63 & 28.25 & 24.75 & 33.25 & 33.00 & 26.50 & 28.50 & 30.13 & 13.13 \\
\hline
\end{tabular}

Note: ${ }^{*} \phi=34.63$, refer Equation (2).

Table A2. Direct relation influence matrix $D$.

\begin{tabular}{|c|c|c|c|c|c|c|c|c|c|c|c|c|c|c|}
\hline & $A_{1}$ & $A_{2}$ & $A_{3}$ & $A_{4}$ & $A_{5}$ & $A_{6}$ & $A_{7}$ & $A_{8}$ & $A_{9}$ & $A_{10}$ & $A_{11}$ & $A_{12}$ & $A_{13}$ & $A_{14}$ \\
\hline$A_{1}$ & 0.000 & 0.087 & 0.058 & 0.061 & 0.083 & 0.061 & 0.087 & 0.032 & 0.054 & 0.036 & 0.032 & 0.058 & 0.036 & 0.018 \\
\hline$A_{2}$ & 0.112 & 0.000 & 0.036 & 0.036 & 0.087 & 0.032 & 0.036 & 0.032 & 0.083 & 0.087 & 0.058 & 0.061 & 0.105 & 0.032 \\
\hline$A_{3}$ & 0.065 & 0.032 & 0.000 & 0.083 & 0.029 & 0.032 & 0.061 & 0.087 & 0.101 & 0.097 & 0.058 & 0.058 & 0.083 & 0.014 \\
\hline$A_{4}$ & 0.032 & 0.040 & 0.079 & 0.000 & 0.032 & 0.036 & 0.032 & 0.040 & 0.087 & 0.097 & 0.061 & 0.083 & 0.083 & 0.022 \\
\hline$A_{5}$ & 0.058 & 0.032 & 0.058 & 0.058 & 0.000 & 0.036 & 0.058 & 0.058 & 0.054 & 0.032 & 0.036 & 0.032 & 0.083 & 0.011 \\
\hline$A_{6}$ & 0.058 & 0.058 & 0.108 & 0.083 & 0.058 & 0.000 & 0.108 & 0.058 & 0.083 & 0.083 & 0.036 & 0.040 & 0.036 & 0.022 \\
\hline$A_{7}$ & 0.036 & 0.032 & 0.087 & 0.032 & 0.083 & 0.101 & 0.000 & 0.058 & 0.079 & 0.101 & 0.083 & 0.090 & 0.032 & 0.014 \\
\hline$A_{8}$ & 0.036 & 0.058 & 0.058 & 0.032 & 0.036 & 0.032 & 0.058 & 0.000 & 0.079 & 0.032 & 0.029 & 0.036 & 0.018 & 0.018 \\
\hline$A_{9}$ & 0.036 & 0.058 & 0.058 & 0.054 & 0.036 & 0.058 & 0.061 & 0.058 & 0.000 & 0.079 & 0.054 & 0.043 & 0.061 & 0.022 \\
\hline$A_{10}$ & 0.065 & 0.101 & 0.097 & 0.101 & 0.094 & 0.054 & 0.032 & 0.036 & 0.061 & 0.000 & 0.087 & 0.101 & 0.090 & 0.014 \\
\hline$A_{11}$ & 0.029 & 0.087 & 0.040 & 0.040 & 0.032 & 0.032 & 0.058 & 0.032 & 0.058 & 0.087 & 0.000 & 0.108 & 0.090 & 0.029 \\
\hline$A_{12}$ & 0.040 & 0.083 & 0.058 & 0.065 & 0.079 & 0.029 & 0.083 & 0.079 & 0.076 & 0.101 & 0.083 & 0.000 & 0.094 & 0.054 \\
\hline$A_{13}$ & 0.032 & 0.032 & 0.087 & 0.065 & 0.083 & 0.083 & 0.083 & 0.090 & 0.087 & 0.083 & 0.087 & 0.079 & 0.000 & 0.108 \\
\hline$A_{14}$ & 0.029 & 0.018 & 0.054 & 0.029 & 0.040 & 0.065 & 0.058 & 0.054 & 0.058 & 0.036 & 0.061 & 0.032 & 0.058 & 0.000 \\
\hline
\end{tabular}


Table A3. Inverse of $(I-D)$.

\begin{tabular}{|c|c|c|c|c|c|c|c|c|c|c|c|c|c|c|}
\hline & $A_{1}$ & $A_{2}$ & $A_{3}$ & $A_{4}$ & $A_{5}$ & $A_{6}$ & $A_{7}$ & $A_{8}$ & $A_{9}$ & $A_{10}$ & $A_{11}$ & $A_{12}$ & $A_{13}$ & $A_{14}$ \\
\hline$A_{1}$ & 1.148 & 0.246 & 0.254 & 0.230 & 0.256 & 0.207 & 0.263 & 0.196 & 0.268 & 0.256 & 0.208 & 0.245 & 0.236 & 0.106 \\
\hline$A_{2}$ & 0.268 & 1.192 & 0.261 & 0.233 & 0.285 & 0.202 & 0.244 & 0.219 & 0.321 & 0.326 & 0.256 & 0.275 & 0.324 & 0.136 \\
\hline$A_{3}$ & 0.224 & 0.225 & 1.228 & 0.275 & 0.230 & 0.202 & 0.264 & 0.268 & 0.340 & 0.340 & 0.258 & 0.274 & 0.303 & 0.118 \\
\hline$A_{4}$ & 0.185 & 0.218 & 0.285 & 1.186 & 0.220 & 0.192 & 0.224 & 0.215 & 0.310 & 0.325 & 0.248 & 0.282 & 0.292 & 0.119 \\
\hline$A_{5}$ & 0.180 & 0.176 & 0.229 & 0.205 & 1.154 & 0.166 & 0.214 & 0.199 & 0.241 & 0.223 & 0.189 & 0.198 & 0.249 & 0.091 \\
\hline$A_{6}$ & 0.226 & 0.249 & 0.335 & 0.281 & 0.261 & 1.175 & 0.311 & 0.248 & 0.332 & 0.336 & 0.243 & 0.263 & 0.268 & 0.123 \\
\hline$A_{7}$ & 0.207 & 0.232 & 0.317 & 0.240 & 0.286 & 0.267 & 1.216 & 0.250 & 0.329 & 0.353 & 0.286 & 0.309 & 0.269 & 0.118 \\
\hline$A_{8}$ & 0.144 & 0.179 & 0.202 & 0.160 & 0.166 & 0.143 & 0.190 & 1.123 & 0.236 & 0.196 & 0.160 & 0.176 & 0.167 & 0.083 \\
\hline$A_{9}$ & 0.178 & 0.219 & 0.251 & 0.222 & 0.209 & 0.201 & 0.236 & 0.216 & 1.213 & 0.290 & 0.226 & 0.230 & 0.254 & 0.110 \\
\hline$A_{10}$ & 0.256 & 0.316 & 0.352 & 0.324 & 0.322 & 0.245 & 0.273 & 0.255 & 0.346 & 1.294 & 0.316 & 0.348 & 0.354 & 0.137 \\
\hline$A_{11}$ & 0.184 & 0.261 & 0.250 & 0.223 & 0.225 & 0.190 & 0.248 & 0.208 & 0.286 & 0.317 & 1.193 & 0.306 & 0.300 & 0.128 \\
\hline$A_{12}$ & 0.226 & 0.294 & 0.312 & 0.284 & 0.304 & 0.222 & 0.311 & 0.287 & 0.351 & 0.377 & 0.309 & 1.250 & 0.347 & 0.169 \\
\hline$A_{13}$ & 0.228 & 0.259 & 0.354 & 0.297 & 0.316 & 0.282 & 0.328 & 0.311 & 0.377 & 0.376 & 0.324 & 0.334 & 1.273 & 0.223 \\
\hline$A_{14}$ & 0.148 & 0.158 & 0.220 & 0.174 & 0.185 & 0.188 & 0.210 & 0.191 & 0.237 & 0.220 & 0.207 & 0.192 & 0.220 & 1.076 \\
\hline
\end{tabular}

Note: $\boldsymbol{I}$ denotes the identity matrix in $(\boldsymbol{I}-\boldsymbol{D})^{-1}$.

Table A4. Total influence relation matrix $T$.

\begin{tabular}{|c|c|c|c|c|c|c|c|c|c|c|c|c|c|c|c|}
\hline & $A_{1}$ & $A_{2}$ & $A_{3}$ & $A_{4}$ & $A_{5}$ & $A_{6}$ & $A_{7}$ & $A_{8}$ & $A_{9}$ & $A_{10}$ & $A_{11}$ & $A_{12}$ & $A_{13}$ & $A_{14}$ & $r_{i}^{A}$ \\
\hline$A_{1}$ & 0.15 & 0.25 & 0.25 & 0.23 & 0.26 & 0.21 & 0.26 & 0.20 & 0.27 & 0.26 & 0.21 & 0.24 & 0.24 & 0.11 & 3.12 \\
\hline$A_{2}$ & 0.27 & 0.19 & 0.26 & 0.23 & 0.29 & 0.20 & 0.24 & 0.22 & 0.32 & 0.33 & 0.26 & 0.28 & 0.32 & 0.14 & 3.54 \\
\hline$A_{3}$ & 0.22 & 0.22 & 0.23 & 0.28 & 0.23 & 0.20 & 0.26 & 0.27 & 0.34 & 0.34 & 0.26 & 0.27 & 0.30 & 0.12 & 3.55 \\
\hline$A_{4}$ & 0.18 & 0.22 & 0.29 & 0.19 & 0.22 & 0.19 & 0.22 & 0.21 & 0.31 & 0.32 & 0.25 & 0.28 & 0.29 & 0.12 & 3.30 \\
\hline$A_{5}$ & 0.18 & 0.18 & 0.23 & 0.20 & 0.15 & 0.17 & 0.21 & 0.20 & 0.24 & 0.22 & 0.19 & 0.20 & 0.25 & 0.09 & 2.71 \\
\hline$A_{6}$ & 0.23 & 0.25 & 0.33 & 0.28 & 0.26 & 0.18 & 0.31 & 0.25 & 0.33 & 0.34 & 0.24 & 0.26 & 0.27 & 0.12 & 3.65 \\
\hline$A_{7}$ & 0.21 & 0.23 & 0.32 & 0.24 & 0.29 & 0.27 & 0.22 & 0.25 & 0.33 & 0.35 & 0.29 & 0.31 & 0.27 & 0.12 & 3.68 \\
\hline$A_{8}$ & 0.14 & 0.18 & 0.20 & 0.16 & 0.17 & 0.14 & 0.19 & 0.12 & 0.24 & 0.20 & 0.16 & 0.18 & 0.17 & 0.08 & 2.33 \\
\hline$A_{9}$ & 0.18 & 0.22 & 0.25 & 0.22 & 0.21 & 0.20 & 0.24 & 0.22 & 0.21 & 0.29 & 0.23 & 0.23 & 0.25 & 0.11 & 3.05 \\
\hline$A_{10}$ & 0.26 & 0.32 & 0.35 & 0.32 & 0.32 & 0.25 & 0.27 & 0.25 & 0.35 & 0.29 & 0.32 & 0.35 & 0.35 & 0.14 & 4.14 \\
\hline$A_{11}$ & 0.18 & 0.26 & 0.25 & 0.22 & 0.22 & 0.19 & 0.25 & 0.21 & 0.29 & 0.32 & 0.19 & 0.31 & 0.30 & 0.13 & 3.32 \\
\hline$A_{12}$ & 0.23 & 0.29 & 0.31 & 0.28 & 0.30 & 0.22 & 0.31 & 0.29 & 0.35 & 0.38 & 0.31 & 0.25 & 0.35 & 0.17 & 4.04 \\
\hline$A_{13}$ & 0.23 & 0.26 & 0.35 & 0.30 & 0.32 & 0.28 & 0.33 & 0.31 & 0.38 & 0.38 & 0.32 & 0.33 & 0.27 & 0.22 & 4.28 \\
\hline$A_{14}$ & 0.15 & 0.16 & 0.22 & 0.17 & 0.19 & 0.19 & 0.21 & 0.19 & 0.24 & 0.22 & 0.21 & 0.19 & 0.22 & 0.08 & 2.63 \\
\hline$s_{j}^{A}$ & 2.80 & 3.22 & 3.85 & 3.33 & 3.42 & 2.88 & 3.53 & 3.18 & 4.19 & 4.23 & 3.42 & 3.68 & 3.86 & 1.74 & \\
\hline
\end{tabular}

Note: Since $T$ is a square matrix, therefore, $i=j=1,2, \ldots, 14$.

Table A5. Un-weighted super-matrix $W$.

\begin{tabular}{|c|c|c|c|c|c|c|c|c|c|c|c|c|c|c|}
\hline & $A_{1}$ & $A_{2}$ & $A_{3}$ & $A_{4}$ & $A_{5}$ & $A_{6}$ & $A_{7}$ & $A_{8}$ & $A_{9}$ & $A_{10}$ & $A_{11}$ & $A_{12}$ & $A_{13}$ & $A_{14}$ \\
\hline$A_{1}$ & 1.148 & 0.246 & 0.254 & 0.230 & 0.256 & 0.207 & 0.263 & 0.196 & 0.268 & 0.256 & 0.208 & 0.245 & 0.236 & 0.106 \\
\hline$A_{2}$ & 0.268 & 1.192 & 0.261 & 0.233 & 0.285 & 0.202 & 0.244 & 0.219 & 0.321 & 0.326 & 0.256 & 0.275 & 0.324 & 0.136 \\
\hline$A_{3}$ & 0.224 & 0.225 & 1.228 & 0.275 & 0.230 & 0.202 & 0.264 & 0.268 & 0.340 & 0.340 & 0.258 & 0.274 & 0.303 & 0.118 \\
\hline$A_{4}$ & 0.185 & 0.218 & 0.285 & 1.186 & 0.220 & 0.192 & 0.224 & 0.215 & 0.310 & 0.325 & 0.248 & 0.282 & 0.292 & 0.119 \\
\hline$A_{5}$ & 0.180 & 0.176 & 0.229 & 0.205 & 1.154 & 0.166 & 0.214 & 0.199 & 0.241 & 0.223 & 0.189 & 0.198 & 0.249 & 0.091 \\
\hline$A_{6}$ & 0.226 & 0.249 & 0.335 & 0.281 & 0.261 & 1.175 & 0.311 & 0.248 & 0.332 & 0.336 & 0.243 & 0.263 & 0.268 & 0.123 \\
\hline$A_{7}$ & 0.207 & 0.232 & 0.317 & 0.240 & 0.286 & 0.267 & 1.216 & 0.250 & 0.329 & 0.353 & 0.286 & 0.309 & 0.269 & 0.118 \\
\hline$A_{8}$ & 0.144 & 0.179 & 0.202 & 0.160 & 0.166 & 0.143 & 0.190 & 1.123 & 0.236 & 0.196 & 0.160 & 0.176 & 0.167 & 0.083 \\
\hline$A_{9}$ & 0.178 & 0.219 & 0.251 & 0.222 & 0.209 & 0.201 & 0.236 & 0.216 & 1.213 & 0.290 & 0.226 & 0.230 & 0.254 & 0.110 \\
\hline$A_{10}$ & 0.256 & 0.316 & 0.352 & 0.324 & 0.322 & 0.245 & 0.273 & 0.255 & 0.346 & 1.294 & 0.316 & 0.348 & 0.354 & 0.137 \\
\hline$A_{11}$ & 0.184 & 0.261 & 0.250 & 0.223 & 0.225 & 0.190 & 0.248 & 0.208 & 0.286 & 0.317 & 1.193 & 0.306 & 0.300 & 0.128 \\
\hline$A_{12}$ & 0.226 & 0.294 & 0.312 & 0.284 & 0.304 & 0.222 & 0.311 & 0.287 & 0.351 & 0.377 & 0.309 & 1.250 & 0.347 & 0.169 \\
\hline$A_{13}$ & 0.228 & 0.259 & 0.354 & 0.297 & 0.316 & 0.282 & 0.328 & 0.311 & 0.377 & 0.376 & 0.324 & 0.334 & 1.273 & 0.223 \\
\hline$A_{14}$ & 0.148 & 0.158 & 0.220 & 0.174 & 0.185 & 0.188 & 0.210 & 0.191 & 0.237 & 0.220 & 0.207 & 0.192 & 0.220 & 1.076 \\
\hline
\end{tabular}

Note: $A_{i}$ denotes the $i$ th attribute, for $i=1,2, \ldots, 14$.

Table A6. Normalized directional influence relation matrix $\boldsymbol{T}_{D}^{\alpha}$.

\begin{tabular}{cccccc}
\hline & $\boldsymbol{D}_{\mathbf{1}}$ & $\boldsymbol{D}_{\mathbf{2}}$ & $\boldsymbol{D}_{\mathbf{3}}$ & $\boldsymbol{D}_{\mathbf{4}}$ & $\boldsymbol{D}_{\mathbf{5}}$ \\
\hline $\boldsymbol{D}_{\mathbf{1}}$ & 0.1828 & 0.2167 & 0.2054 & 0.2234 & 0.1717 \\
$\boldsymbol{D}_{\mathbf{2}}$ & 0.1802 & 0.2003 & 0.2117 & 0.2327 & 0.1751 \\
$\boldsymbol{D}_{\mathbf{3}}$ & 0.1843 & 0.2202 & 0.2077 & 0.2307 & 0.1570 \\
$\boldsymbol{D}_{\mathbf{4}}$ & 0.1892 & 0.2132 & 0.1984 & 0.2224 & 0.1769 \\
$\boldsymbol{D}_{\mathbf{5}}$ & 0.1660 & 0.2158 & 0.2221 & 0.2305 & 0.1656 \\
\hline
\end{tabular}


Table A7. Initial weighted super-matrix $W^{N}\left(W^{N}=T_{D}^{\alpha} \times W\right)$.

\begin{tabular}{|c|c|c|c|c|c|c|c|c|c|c|c|c|c|c|}
\hline & $A_{1}$ & $A_{2}$ & $A_{3}$ & $A_{4}$ & $A_{5}$ & $A_{6}$ & $A_{7}$ & $A_{8}$ & $A_{9}$ & $A_{10}$ & $A_{11}$ & $A_{12}$ & $A_{13}$ & $A_{14}$ \\
\hline$A_{1}$ & 0.068 & 0.106 & 0.090 & 0.083 & 0.092 & 0.087 & 0.087 & 0.083 & 0.083 & 0.085 & 0.078 & 0.083 & 0.078 & 0.080 \\
\hline$A_{2}$ & 0.115 & 0.077 & 0.090 & 0.097 & 0.088 & 0.098 & 0.098 & 0.101 & 0.101 & 0.104 & 0.112 & 0.106 & 0.088 & 0.086 \\
\hline$A_{3}$ & 0.074 & 0.074 & 0.062 & 0.082 & 0.078 & 0.084 & 0.084 & 0.084 & 0.081 & 0.075 & 0.077 & 0.075 & 0.080 & 0.082 \\
\hline$A_{4}$ & 0.067 & 0.065 & 0.076 & 0.054 & 0.070 & 0.070 & 0.062 & 0.066 & 0.073 & 0.068 & 0.068 & 0.068 & 0.067 & 0.065 \\
\hline$A_{5}$ & 0.076 & 0.080 & 0.062 & 0.064 & 0.052 & 0.066 & 0.075 & 0.068 & 0.068 & 0.068 & 0.068 & 0.072 & 0.071 & 0.069 \\
\hline$A_{6}$ & 0.045 & 0.043 & 0.040 & 0.042 & 0.042 & 0.033 & 0.052 & 0.044 & 0.048 & 0.044 & 0.040 & 0.038 & 0.049 & 0.051 \\
\hline$A_{7}$ & 0.058 & 0.051 & 0.053 & 0.051 & 0.055 & 0.060 & 0.042 & 0.056 & 0.056 & 0.048 & 0.054 & 0.054 & 0.056 & 0.056 \\
\hline$A_{8}$ & 0.043 & 0.045 & 0.053 & 0.049 & 0.051 & 0.048 & 0.050 & 0.037 & 0.052 & 0.046 & 0.044 & 0.050 & 0.053 & 0.051 \\
\hline$A_{9}$ & 0.060 & 0.068 & 0.068 & 0.070 & 0.061 & 0.064 & 0.064 & 0.071 & 0.052 & 0.062 & 0.062 & 0.060 & 0.064 & 0.064 \\
\hline$A_{10}$ & 0.080 & 0.085 & 0.091 & 0.088 & 0.086 & 0.092 & 0.085 & 0.085 & 0.090 & 0.069 & 0.087 & 0.089 & 0.083 & 0.083 \\
\hline$A_{11}$ & 0.065 & 0.067 & 0.070 & 0.067 & 0.072 & 0.067 & 0.069 & 0.069 & 0.069 & 0.073 & 0.053 & 0.073 & 0.071 & 0.076 \\
\hline$A_{12}$ & 0.078 & 0.071 & 0.072 & 0.077 & 0.074 & 0.072 & 0.076 & 0.076 & 0.072 & 0.080 & 0.085 & 0.060 & 0.074 & 0.071 \\
\hline$A_{13}$ & 0.118 & 0.120 & 0.126 & 0.124 & 0.128 & 0.108 & 0.108 & 0.105 & 0.110 & 0.127 & 0.124 & 0.119 & 0.091 & 0.123 \\
\hline$A_{14}$ & 0.053 & 0.052 & 0.049 & 0.051 & 0.047 & 0.049 & 0.049 & 0.052 & 0.047 & 0.050 & 0.053 & 0.058 & 0.075 & 0.043 \\
\hline
\end{tabular}

\section{References}

1. Griliches, Z. Productivity, R\&D, and basic research at the firm Level in the 1970s. Am. Econ. Rev. 1986, 76, 141-154.

2. Wang, C.H.; Lu, Y.H.; Huang, C.W.; Lee, J.Y. R\&D, productivity, and market value: An empirical study from high-technology firms. Omega 2013, 41, 143-155. [CrossRef]

3. Bommer, M.; Jalajas, D. The innovation work environment of high-tech SMEs in the USA and Canada. R D Manag. 2002, 32, 379-386. [CrossRef]

4. Prajogo, D.I. The relationship between innovation and business performance-A comparative study between manufacturing and service firms. Knowl. Process. Manag. 2006, 13, 218-225. [CrossRef]

5. Yan, M.R. Strategic product innovations and dynamic pricing models in oligopolistic market. J. Sci. Ind. Res. 2017, 76, 284-288.

6. Cho, H.J.; Pucik, V. Relationship between innovativeness, quality, growth, profitability, and market value. Strateg. Manag. J. 2005, 26, 555-575. [CrossRef]

7. Macdonald, S. When means become ends: Considering the impact of patent strategy on innovation. Inf. Econ. Policy 2004, 16, 135-158. [CrossRef]

8. Artz, K.W.; Norman, P.M.; Hatfield, D.E.; Cardinal, L.B. A longitudinal study of the impact of R\&D, patents, and product innovation on firm performance. J. Prod. Innov. Manag. 2010, 27, 725-740. [CrossRef]

9. Yan, M.R.; Chien, K.M.; Yang, T.N. Green component procurement collaboration for improving supply chain management in the high technology industries: A case study from the systems perspective. Sustainability 2016, 8, 105. [CrossRef]

10. US International Trade Administration. Available online: http://trade.gov/topmarkets/pdf/ Semiconductors_Taiwan.pdf (accessed on 31 July 2016).

11. Shen, K.Y. Compromise between short-and long-term financial sustainability: A hybrid model for supporting R\&D decisions. Sustainability 2017, 9, 375. [CrossRef]

12. Lai, Y.L.; Lin, F.J.; Lin, Y.H. Factors affecting firm's R\&D investment decisions. J. Bus. Res. 2015, 68, 840-844.

13. Yan, M.R.; Chien, K.M. Evaluating the economic performance of high-technology industry and energy efficiency: A case study of science parks in Taiwan. Energies 2013, 6, 973-987. [CrossRef]

14. Sher, P.J.; Yang, P.Y. The effects of innovative capabilities and R\&D clustering on firm performance: The evidence of Taiwan's semiconductor industry. Technovation 2005, 25, 33-43.

15. Booth, L.; Ntantamis, C.; Zhou, J. Financial constraints, R\&D investment, and the value of cash holdings. Q. J. Financ. 2015, 5. Available online: http://www.worldscientific.com/doi/abs/10.1142/ S2010139215500111 (accessed on 26 October 2017). [CrossRef]

16. Li, D. Financial constraints, R\&D investment, and stock returns. Rev. Financ. Stud. 2011, 24, 2974-3007.

17. Czarnitzki, D.; Hottenrott, H. R\&D investment and financing constraints of small and medium-sized firms. Small Bus. Econ. 2011, 36, 65-83.

18. Neuhäusler, P.; Frietsch, R.; Schubert, T.; Blind, K. Patents and the Financial Performance of Firms-An Analysis Based on Stock Market Data. Econstor, 2011. Available online: https:/ / www.econstor.eu/handle/ 10419/44995 (accessed on 26 October 2017).

19. Pawlak, Z. Rough sets. Int. J. Comput. Inf. Sci. 1982, 11, 341-356. [CrossRef] 
20. Bello, R.; Falcon, R. Rough sets in machine learning: A review. In Thriving Rough Sets (Studies in Computational Intelligence); Wang, G., Skowron, A., Yao, Y., Ślęzak, D., Polkowski, L., Eds.; Springer: Berlin, Germany, 2017.

21. Greco, S.; Matarazzo, B.; Słowiński, R. Rough approximation by dominance relations. Int. J. Intell. Syst. 2002, 17, 153-171. [CrossRef]

22. Błaszczyński, J.; Słowiński, R.; Szelag, M. Sequential covering rule induction algorithm for variable consistency rough set approaches. Inf. Sci. 2011, 181, 987-1002. [CrossRef]

23. McKee, T.E. Rough sets bankruptcy prediction models versus auditor signaling rates. J. Forecast. 2003, 22, 569-586. [CrossRef]

24. Shen, K.Y.; Tzeng, G.H. A decision rule-based soft computing model for supporting financial performance improvement of the banking industry. Soft Comput. 2015, 19, 859-874. [CrossRef]

25. Shen, K.Y.; Hu, S.K.; Tzeng, G.H. Financial modeling and improvement planning for the life insurance industry by using a rough knowledge based hybrid MCDM model. Inf. Sci. 2017, 375, 296-313. [CrossRef]

26. Shen, K.Y.; Tzeng, G.H. Fuzzy inference enhanced VC-DRSA model for technical analysis: Investment decision aid. Int. J. Fuzzy Syst. 2015, 17, 375-389. [CrossRef]

27. Greco, S.; Matarazzo, B.; Słowiński, R. Beyond Markowitz with multiple criteria decision aiding. J. Bus. Econ. 2013, 83, 29-60. [CrossRef]

28. Shen, K.Y.; Tzeng, G.H. Combining DRSA decision-rules with FCA-based DANP evaluation for financial performance improvements. Technol. Econ. Dev. Econ. 2016, 22, 685-714. [CrossRef]

29. Tzeng, G.H.; Huang, J.J. Multiple Attribute Decision Making: Methods and Applications; CRC Press: New York, NY, USA, 2011.

30. Tzeng, G.H.; Shen, K.Y. New Concepts and Trends of Hybrid Multiple Criteria Decision Making; CRC Press: New York, NY, USA, 2017.

31. Liou, J.J.H.; Tzeng, G.H. Comments on "Multiple criteria decision making (MCDM) methods in economics: An overview". Technol. Econ. Dev. Econ. 2012, 18, 672-695. [CrossRef]

32. Spronk, J.; Steuer, R.E.; Zopounidis, C. Multiple criteria decision aid/analysis in finance. In Multiple Criteria Deci. Analysis: State of the Art Surveys; Figueira, J., Greco, S., Ehrgott, M., Eds.; Springer: New York, NY, USA, 2005.

33. Gabus, A.; Fontela, E. World Problems, an Invitation to Further Thought within the Framework of DEMATEL; Battelle Geneva Research Center: Geneva, Switzerland; 1972.

34. Lee, H.S.; Tzeng, G.H.; Yeih, W.; Wang, Y.J.; Yang, S.C. Revised DEMATEL: Resolving the infeasibility of DEMATEL. Appl. Math. Model. 2013, 37, 6746-6757. [CrossRef]

35. Saaty, T.L. Theory and Applications of the Analytic Network Process: Decision Making. with Benefits, Opportunities, Costs, and Risks; RWS Publications: Pittsburgh, PA, USA, 2005.

36. Zhu, B.W.; Zhang, J.R.; Tzeng, G.H.; Huang, S.L.; Xiong, L. Public open space development for elderly people by using the DANP-V model to establish continuous improvement strategies towards a sustainable and healthy aging society. Sustainability 2017, 9, 420. [CrossRef]

37. Shen, Y.C.; Lin, G.T.; Tzeng, G.H. A novel multi-criteria decision-making combining decision making trial and evaluation laboratory technique for technology evaluation. Foresight 2012, 14, 139-153. [CrossRef]

38. Ou Yang, Y.P.; Shieh, H.M.; Tzeng, G.H. A VIKOR technique based on DEMATEL and ANP for information security risk control assessment. Inf. Sci. 2013, 232, 482-500. [CrossRef]

39. Zeleny, M. Multiple Criteria Decision Making; McGraw-Hill: New York, NY, USA, 1982.

40. Opricovic, S.; Tzeng, G.H. Compromise solution by MCDM methods: A comparative analysis of VIKOR and TOPSIS. Eur. J. Oper. Res. 2004, 156, 445-455. [CrossRef]

41. Błaszczyński, J.; Greco, S.; Matarazzo, B.; Słowiński, R.; Szelag, M. jMAF-Dominance-based rough set data analysis framework. In Rough Sets and Intelligent Systems-Professor Zdzisław Pawlak in Memoriam (Intelligent Systems Reference Library); Skowron, A., Suraj, Z., Eds.; Springer: Berlin Heidelberg, Germany, 2013.

42. Taiwan Economic Journal (TEJ). Available online: http://www.finasia.biz/ensite/ (accessed on 31 May 2017).

43. DTREG. The Official Website of the Software Company. Available online: https://www.dtreg.com/ (accessed on 31 May 2017).

(C) 2017 by the authors. Licensee MDPI, Basel, Switzerland. This article is an open access article distributed under the terms and conditions of the Creative Commons Attribution (CC BY) license (http:/ / creativecommons.org/licenses/by/4.0/). 